\title{
LA DUALIDAD CAUTELAR Y SUMARIA DE LA PROTECCIÓN DE DERECHOS FUNDAMENTALES
}

\author{
THE PRECAUTIONARY AND SUMMARY DUALITY OF PROTECTION \\ OF FUNDAMENTAL RIGHTS
}

\section{Jorge Larroucau TORres}

\begin{abstract}
RESUMEN: La protección de los derechos fundamentales adolece de una dualidad procesal ya que su fisonomía oscila entre la que corresponde a una medida cautelar - una orden judicial transitoria, idónea y proporcional-y un juicio sumario -un procedimiento declarativo que conduce a una sentencia con autoridad de cosa juzgada material-. Este artículo indaga en su regulación tanto constitucional como en los autos acordados dictados por la Corte Suprema (en los años 1977, 1992, 1998, 2007 y 2015), en la literatura chilena y en la jurisprudencia reciente de las Cortes con un doble propósito: identificar las consecuencias procesales más significativas que acarrea esta dualidad y evaluar la coherencia interna de cada uno de estos enfoques.
\end{abstract}

Palabras claves: protección, derechos fundamentales, tutela cautelar, juicio sumario, buena fe procesal.

ABSTRACT: The protection of fundamental rights suffers from a procedural duality since its physiognomy ranges from that corresponding to a precautionary measure-a temporary, suitable and proportional court order-and to a summary trial-a declaratory procedure that leading to a judgment that has the force of res judicata-. This article delves into its constitutional regulation as well as in the 'autos acordados' (an order emanating from some superior tribunal, promulgated in the name and by the authority of the sovereign), dictated by the Supreme Court (in the years 1977, 1992, 1998, 2007 and 2015) in the Chilean academic literature and in the recent jurisprudence of the Chilean Courts with a dual purpose: identify the most significant procedural consequences entailed by this duality and value the internal coherence of each of these approaches.

Keywords: protection, fundamental rights, precautionary measure, summary trial, procedural good faith.

\footnotetext{
Doctor en Derecho, Universidad de Chile. Profesor de Derecho Procesal Civil, Pontificia Universidad Católica de Valparaíso. Código Orcid 0000-0001-9893-5450. Dirección postal: Avenida Brasil 2950, Valparaíso, Chile. Dirección electrónica: jorge.larroucau@pucv.cl. Para este artículo fueron muy útiles las discusiones en el módulo "Recurso de Protección" de los Programas de Habilitación Nos 31, 33, 35 y 36 de la Academia Judicial por lo que agradezco a quienes participaron en dichos cursos sus valiosas observaciones y a la Academia Judicial la oportunidad de participar en ellos. Este trabajo es parte de una investigación financiada mediante un proyecto Fondecyt Regular (No 1170067: "El principio de la buena fe procesal. Análisis dogmático y crítico de su rol como fuente de cargas, deberes y sanciones en la formación del debate", 2017-2018) cuyo apoyo también reconozco.
} 


\section{INTRODUCCIÓN}

La tutela judicial que se inicia ante una Corte de Apelaciones y cuyo objeto es el más importante dentro del sistema jurídico chileno - proteger los derechos fundamentales ${ }^{1}$ - adolece de una clara dualidad en términos procesales. Tanto su fisonomía normativa como su uso por parte de jueces y abogados oscila entre la que es propia de una medida cautelar -una orden judicial transitoria, idónea y proporcional- y la de un juicio sumario -un procedimiento declarativo que conduce a una sentencia con autoridad de cosa juzgada material-.

Desde un punto de vista procesal esta inconsistencia vuelve más aguda una tensión que afecta a todo sistema jurídico que contemple una protección judicial de los derechos fundamentales: una pugna entre el derecho de acceso a la justicia o tutela judicial efectiva de quien acude ante un tribunal porque considera afectado un derecho cuya protección no puede demorar y el derecho a un debido proceso que tiene aquel en contra de quien se recurre.

Este artículo indaga críticamente en la regulación que ha tenido la forma de tramitar la protección de derechos fundamentales tanto en el texto constitucional de 1980 como en los diversos autos acordados dictados por la Corte Suprema (en los años 1977, 1992, 1998, 2007 y 2015), en la literatura chilena publicada sobre esta materia durante sus primeras cuatro décadas de vigencia y en la jurisprudencia reciente de las Cortes (la Corte Suprema y la Cortes de Apelaciones) para identificar los efectos procesales más significativos que acarrea esta dualidad y evaluar la coherencia interna de cada uno de estos enfoques, el cautelar y el sumario.

\footnotetext{
${ }^{1}$ Art. 20, Constitución de 1980: "El que por causa de actos u omisiones arbitrarios o ilegales sufra privación, perturbación o amenaza en el legítimo ejercicio de los derechos y garantías establecidos en el artículo 19, números $1^{\circ}$ ["derecho a la vida y a la integridad física y psíquica de la persona"], 2o ["igualdad ante la ley"], $3^{\circ}$ inciso quinto ["Nadie podrá ser juzgado por comisiones especiales, sino por el tribunal que señalare la ley y que se hallare establecido por esta con anterioridad a la perpetración del hecho"], 40 ["respeto y protección a la vida privada y a la honra de la persona y su familia, y asimismo, la protección de sus datos personales"], 50 [“inviolabilidad del hogar y de toda forma de comunicación privada"], 60 ["libertad de conciencia, la manifestación de todas las creencias y el ejercicio libre de todos los cultos que no se opongan a la moral, a las buenas costumbres o al orden público"], 9o inciso final ["el derecho a elegir el sistema de salud al que desee acogerse, sea este estatal o privado"], $11^{\circ}$ ["libertad de enseñanza"], 12 ["libertad de emitir opinión y la de informar, sin censura previa"], $13^{\circ}$ ["derecho a reunirse pacíficamente sin permiso previo y sin armas"], $15^{\circ}$ ["derecho de asociarse sin permiso previo"], $16^{\circ}$ en lo relativo a la libertad de trabajo y al derecho a su libre elección y libre contratación, y a lo establecido en el inciso cuarto, $19^{\circ}$ ["derecho de sindicarse en los casos y forma que señale la ley"], $21^{\circ}$ ["derecho a desarrollar cualquiera actividad económica que no sea contraria a la moral, al orden público o a la seguridad nacional"], 220 "'La no discriminación arbitraria en el trato que deben dar el Estado y sus organismos en materia económica"], 23 ["La libertad para adquirir el dominio de toda clase de bienes, excepto aquellos que la naturaleza ha hecho comunes a todos los hombres o que deban pertenecer a la Nación toda y la ley lo declare así"], $24^{\circ}$ ["El derecho de propiedad en sus diversas especies sobre toda clase de bienes corporales o incorporales"], y 25० ["La libertad de crear y difundir las artes, así como el derecho del autor sobre sus creaciones intelectuales y artísticas de cualquier especie”] podrá ocurrir por sí o por cualquiera a su nombre, a la Corte de Apelaciones respectiva, la que adoptará de inmediato las providencias que juzgue necesarias para restablecer el imperio del derecho y asegurar la debida protección del afectado, sin perjuicio de los demás derechos que pueda hacer valer ante la autoridad o los tribunales correspondientes.

"Procederá, también, el recurso de protección en el caso del № $8^{\circ}$ del artículo 19, cuando el derecho a vivir en un medio ambiente libre de contaminación sea afectado por un acto u omisión ilegal imputable a una autoridad o persona determinada".
} 
El estudio demuestra que las incongruencias procesales creadas por esta dualidad hacen muy difícil que quienes recurren de protección puedan cumplir con las exigencias que impone el principio de buena fe procesal como fuente de cargas y deberes durante la formación del debate, puesto que las pautas de comportamiento que se deben seguir ante el tribunal son diferentes según se trate de una tutela cautelar de urgencia o de un procedimiento declarativo de carácter sumario.

En este sentido el artículo no se ocupa de cuál debería ser la 'naturaleza' de la protección de derechos fundamentales sino que su objetivo es distinguir las consecuencias prácticas que conllevan una concepción cautelar y otra sumaria de esta tutela judicial. Por este motivo los fallos que se citan provienen especialmente de la segunda década de este siglo ya que la fisonomía sumaria de la protección se hizo aún más patente con la tramitación que dispuso el Acta No 94 del año 2015, por lo que las decisiones judiciales anteriores y posteriores a este año son suficientes para ilustrar el modo en que estas dos formas de entender a la protección de derechos fundamentales distorsionan el trabajo de las Cortes.

El estudio concluye con una síntesis de las principales incongruencias procesales que se observan entre el art. 20 de la Constitución de 1980, los autos acordados de la Corte Suprema y la ley procesal que se aplica residualmente a la protección -el Código de Procedimiento Civil del año 1903 (CPC)-, así como con una crítica dogmática al proyecto de ley presentado en el año 2001 al Congreso para regular su tramitación y que constituye el único intento de regulación legal que ha sido discutido con cierto detalle hasta la fecha. Este proyecto no solo mantiene, sino que agudiza, la dualidad cautelar y sumaria que afecta a la protección de derechos fundamentales y con ello incrementa las confusiones acerca de su tramitación.

\section{II. ¿TUTELA CAUTELAR O JUICIO SUMARIO?}

La protección del art. 20 de la Constitución de 1980 ha recibido varios nombres a lo largo de sus cuatro primeras décadas de vigencia. Esta disparidad no es un asunto menor sino que refleja las múltiples formas en que ella puede ser concebida: una acción para litigar en un juicio civil, un recurso procesal ante una Corte o bien una vía expedita para conseguir una orden judicial frente a un hecho que amenaza, perturba o priva a alguien de uno de sus derechos fundamentales ${ }^{2}$.

El consenso se agota en que la protección no debe entenderse como un recurso procesal ya que ella no opera como un medio para impugnar un fallo de modo que la respuesta de las Cortes en este caso debe ser, en principio, declarar inadmisible la protección ${ }^{3}$. Por lo tanto dicha dimensión queda fuera de este análisis a pesar de que el propio texto constitucional de 1980 hablase de "recurso de protección" (art. 20 inciso 2). El debate se circunscribe a las otras dos opciones: la protección es una tutela cautelar o bien un juicio sumario.

En la academia chilena algunos estudios han tomado posición a este respecto, pero no han desarrollado las consecuencias procesales que ella implica. Un ejemplo de esto es lo

\footnotetext{
2 Henríquez (2018) pp. 3-6.

3 Larroucau (2020) pp. 15-19.
} 
que sostuvieron a mediados de los años noventa Andrés Jana y Juan Carlos Marín en cuanto a que:

"el RP [recurso de protección] no es una acción cautelar, tiene la naturaleza de una acción principal [y] las acciones cautelares no son principales, sino que, como hemos visto, son esencialmente accesorias [...] Tratándose del RP creemos que él no solo tiene autonomía desde el punto de vista conceptual, sino además funcional, esto es, no está al servicio de ningún otro proceso, por lo que no encuadra en aquella pretendida categoría de procesos cautelares autónomos”“.

Esta observación es importante porque en el ordenamiento jurídico chileno ambas categorías -la acción en un juicio declarativo y la tutela cautelar- están diferenciadas. Así, por ejemplo, el juicio sumario es un procedimiento de cognición que sirve para declarar derechos, deberes y obligaciones entre las partes (Título XI, Libro III del Código de Procedimiento Civil de 1903) mientras que la tutela cautelar es una técnica procesal para asegurar un bien ante un peligro, algo que el Código de 1903 solo reguló a propósito de una de sus modalidades: las medidas cautelares conservativas o precautorias (Título V, Libro II).

Por lo tanto, si se quiere dar cuenta de los efectos procesales que se siguen de estas dos aproximaciones a la protección de derechos fundamentales es necesario abandonar la concepción amplia de la tutela judicial sumaria como una que la asimila a la tutela cautelar ${ }^{5}$. Esto permitirá reconocer las diferencias entre una tramitación sumaria y la técnica cautelar en el campo de la protección, sin perjuicio de que en un sentido amplio ella sea una forma más de impedir la autotutela ${ }^{6}$.

Para avanzar a este respecto es preciso recordar que la protección fue regulada por primera vez - al menos en su forma actual- a fines de los años setenta como una ampliación del amparo hacia otros derechos fundamentales diversos de la libertad personal y la seguridad individual dado que estos últimos ya contaban para su resguardo con el habeas corpus. $\mathrm{Si}$ bien es posible reconocer algunos antecedentes más o menos lejanos en otros preceptos de la legislación previa como la protección de las "garantías individuales" que el art. 146 de la Constitución de 1823 le entregó a la Corte Suprema ${ }^{7}$ y sin perjuicio de su equivalencia funcional con otras figuras procesales de la legislación comparada como el référé francés ${ }^{8}$, el amparo argentino ${ }^{9}$, el amparo mexicano y el mandado de segurança brasileño ${ }^{10}$, lo cierto es que la protección del art. 20 de la Constitución de 1980 tuvo con el correr de los años una evolución propia que es importante para este análisis.

Este desarrollo se dio a través de tres fases de expansión que denotan su dualidad cautelar y sumaria. En efecto, aunque esta tutela judicial comenzó a operar rápidamente

4 Jana y Marín (1996) pp. 75-76 y 82 (nota 63).

5 Pérez (2017) pp. 147-154 y 168-173.

6 Por todos, Palomo (2009) p. 348.

7 Zúniga (1996) pp. 8-12.

8 PAillás (2002) pp. 17-45.

9 Pinochet (2016) pp. 71-101.

10 Nogueira (2007) pp. 75-134. 
como un sucedáneo de un procedimiento contencioso administrativo (i.e., como una acción en contra de la Administración del Estado) en poco tiempo adquirió un uso cada vez más frecuente como una vía judicial para evitar la autotutela entre particulares (i.e., una tutela cautelar de urgencia) y, durante la segunda década de este siglo, ha sido utilizada incluso como una tutela cautelar transfronteriza ${ }^{11}$. En otras palabras, se trata de una evolución judicial que expresa la dualidad cautelar y sumaria con un claro acento puesto en lo primero.

\section{TUTELA CAUTELAR}

El mejor fundamento normativo para una concepción cautelar de la protección se encuentra en su primer auto acordado, el del año 1977, así como en el propio texto constitucional de 1980.

La Corte Suprema reguló la protección por primera vez en abril de 1977 gracias a que el Acta Constitucional de 1976 (art. 2 inciso 2) la autorizó para hacerse cargo de la "tramitación” de la protección, algo que un año antes -en 1975- también había sido dispuesto por el Anteproyecto de la Comisión de Estudio de la Nueva Constitución (art. 20 inciso 3).

El que su procedimiento se haya diseñado a través de autos acordados es una cuestión muy polémica y, a pesar de su clara conexión con el propósito de este artículo, no será abordada en lo que sigue. Al respecto solo cabe anotar tres cuestiones generales. En primer lugar, las reglas posteriores al auto acordado de 1977 tendrían "una precaria base jurídica"12 debido a que la Constitución de 1980 no reiteró la facultad del Acta Constitucional de $1976^{13}$, una omisión que incluso podría haber derogado tácitamente el auto acordado de $1977^{14}$. Como segundo punto es significativo advertir que el Tribunal Constitucional no suele cuestionar la constitucionalidad de esta técnica regulatoria cuando conoce de los requerimientos de inaplicabilidad en contra de los autos acordados de las Cortes ${ }^{15}$. Y, en tercer término, sirve tener en cuenta que en Chile es posible regular un aspecto del procedimiento judicial mediante auto acordado si se toma como punto de partida una distinción conceptual entre garantías, principios y reglas procesales de acuerdo con el texto constitucional de $1980^{16}$.

Lo que ahora importa considerar es que el enfoque cautelar del auto acordado de 1977 y del art. 20 de la Constitución de 1980 fue rápidamente reconocido por la jurisprudencia y por la dogmática chilenas ${ }^{17}$. En este sentido la protección pasó a ser caracterizado como un medio de tutela "informal, inquisitivo, unilateral, breve y concentrado, abierto y provisorio" 18 .

\footnotetext{
11 Larroucau (2019a) pp. 252-277.

12 Andrades (1998) p. 123.

13 Precht (1992) pp. 53-64.

14 Pinochet (2016) pp. 300-301.

15 ZúNiga (2011) pp. 389-417.

16 Larroucau (2017) pp. 201-211 y 219-228.

17 Por todos, Errázuriz y Otero (1989) pp. 34-37.

18 Ríos (1994) p. 45.
} 
Las consecuencias prácticas que derivan de esta aproximación cautelar no se hicieron esperar. Entre ellas se pueden destacar - por ahora- las siguientes: la protección tiene un ámbito de aplicación muy amplio ya que procede incluso ante una amenaza siempre que sea seria e inminente ${ }^{19}$, pues entre sus objetivos no se encuentra la indemnización de perjuicios. En cuanto a su forma de presentación basta con recurrir de manera verbal ${ }^{20}$, lo que la asemeja a una especie de denuncia ${ }^{21}$.

En lo que respecta a su legitimación pasiva la protección procede en contra de alguien indeterminado en cuyo caso la Corte puede solicitar a cualquier persona los antecedentes que estime necesarios para decidir (No 8 inciso 1º, Acta No 94 de 2015). Este último aspecto se vio fortalecido con el auto acordado de 2018 en que la Corte Suprema amplió a las Cortes de Apelaciones la potestad de solicitar informes a terceros que puedan ser afectados por la decisión (Acta No 173).

La Corte de Apelaciones también puede dictar "de inmediato" cualquier medida cautelar aunque no haya sido pedida por el recurrente y sin que ello exponga su fallo a la nulidad por ultrapetita. El informe que evacúa el recurrido de protección, en tanto, lo hace "como un tercero ajeno al proceso" 22 , un tercero excluyente ${ }^{23}$, no como parte, ya que no se trata de un procedimiento contencioso.

Esta concepción cautelar de la protección de derechos fundamentales tuvo una variante radical a fines de los años ochenta en la tesis de Juan Manuel Errázuriz y Jorge Otero según la cual el sujeto pasivo de la protección es la propia Corte ante la cual se recurre ${ }^{24}$. Una de las consecuencias inmediatas de esta tesis radical es que la carga de la prueba no recae en quien recurre de protección, ni tampoco en el recurrido, sino que en el mismo tribunal ${ }^{25}$.

Para un enfoque cautelar la protección es una expresión paradigmática de las facultades conservadoras de los tribunales (art. 3, Código Orgánico de Tribunales del año 1943, $\mathrm{COT}^{26}$ ) de modo que no corresponde analizar su tramitación con las categorías del procedimiento contencioso. Así, por ejemplo, sería erróneo tenerla por no presentada porque la persona que recurre no cuenta con el patrocinio de un abogado, como sí ha ocurrido en algunas ocasiones ${ }^{27}$.

Para el punto de vista cautelar la protección "no da origen a un proceso contencioso sino a una relación jurídica que se desarrolla entre el particular y la Jurisdicción” y en ella la orden judicial tiene un fin "equivalente al 'atrás sin golpes' del boxeo, esto es, poner a las partes en condiciones de solucionar su controversia por medios jurídicamente idóneos”28.

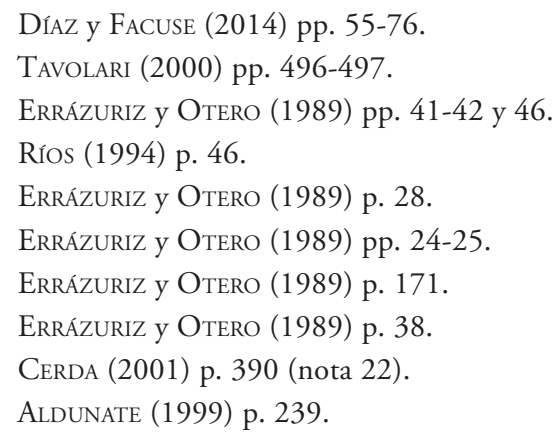


En la imagen que da Raúl Tavolari la protección se asemeja a "la atención de salud de urgencia que el Estado dispensa"29.

El Tribunal Constitucional chileno por su parte ha refrendado esta concepción cautelar de la protección, por ejemplo, a raíz de un caso en que se pidió la remoción de unos concejales por haber recurrido en contra de su Municipio debido a una supuesta discriminación hacia un colegio particular subvencionado con respecto al uso de un gimnasio municipal. El Tribunal Constitucional sostuvo que la prohibición legal que pesa sobre los concejales en términos de que no pueden actuar como abogados "en cualquier clase de juicio" en contra del Municipio no les impedía interponer una protección porque esta vía no persigue la declaración de un derecho, ni tampoco comparecen en ella como mandatarios de los afectados sino como agentes oficiosos para la tutela de un derecho fundamental (cons. 230 ${ }^{30}$.

Lo anterior da una imagen general del modo en que se puede usar la protección ante una Corte en su rol de tutela cautelar. Esta fisonomía acota las pautas de actuación que se derivan del principio de buena fe procesal tanto para quien recurre de protección como para quien aparece como recurrido ante el tribunal ${ }^{31}$. Para perfilar de mejor manera esta noción es útil detenerse en los dos aspectos en que la impronta cautelar de la protección de derechos fundamentales tiene un mayor impacto procesal si se le compara con el enfoque sumario: el acceso al tribunal (con los filtros de admisibilidad) y la eficacia de la decisión (a propósito de la cosa juzgada).

\section{FILTROS DE ADMISIBILIDAD}

El intenso uso de la protección a partir de los años noventa llevó a que la Corte Suprema introdujera un filtro de admisibilidad en este campo. Ello ocurrió en el año 1998 cuando la Sala pudo declarar -por unanimidad- que la protección era inadmisible por "extemporánea" o porque adolecía de "manifiesta falta de fundamento". Esta decisión debía ser "someramente fundada" (No 1, auto acordado de 1998).

Casi una década después, en el auto acordado del año 2007, la Corte Suprema modificó este filtro de admisibilidad al señalar que la Sala debe decidir si la protección se interpuso "en tiempo y si se mencionan hechos que puedan constituir la vulneración de garantías” reconocidas en el art. 20 de la Constitución de 1980. Esta decisión debe ser fundada y admite una reposición en su contra dentro de tercero día (I, auto acordado de 2007).

En el año 2015 se dispuso que la resolución que declara inadmisible una protección es apelable en subsidio de la reposición ante la Corte Suprema la cual decide en cuenta (No 2, Acta No 94 de 2015) pero no se dijo nada acerca del tipo de plazo de que se trata. En mi opi-

\footnotetext{
29 TAVOlari (2000) pp. 481-482 (nota 559).

30 REQUERIMIENTO DE INAPLICABILIDAD PRESENTADO POR CRISTIAN HERRERA Y RAÚl SCHIFFERLI RESPECTO DE LA LETRA B) DEL INCISO $2^{\circ}$ DEL ARTÍCULO 75 DE LA LEY No 18.695 (2014) analizada en BordALí (2014) pp. 277-283.

31 Art. 2 letra d), Ley No 20.886 del año 2015, modifica el Código de Procedimiento Civil, para establecer la tramitación digital de los procedimientos judiciales: "Buena fe procesal. Las partes, sus apoderados y todos quienes intervengan en el proceso deberán actuar de buena fe.

"El tribunal, de oficio o a petición de parte, deberá prevenir, corregir y sancionar, según corresponda, toda acción u omisión que importe un fraude o abuso procesal, colusión, contravención de actos propios o cualquiera otra conducta ilícita, dilatoria o de cualquier otro modo contraria a la buena fe".
} 
nión este plazo para reponer y para apelar en subsidio debe ser entendido como uno discontinuo por aplicación del Libro I del Código de 1903 ("Disposiciones comunes a todo procedimiento", art. 66) y no como uno continuo que sería el resultado de aplicar supletoriamente el Código de Bello de 1857 (art. 50). Esta última fue la idea de Errázuriz y Otero ${ }^{32}$.

La presencia de este filtro de admisibilidad es clave para la dualidad cautelar y sumaria de la protección ya que la oportunidad procesal para aplicar la verosimilitud del derecho (fumus boni iuris) o el peligro en la demora (periculum in mora) es distinta en uno y otro caso. En efecto, (1) bajo una concepción cautelar la Corte propende a conocer la protección y a decidir en su fallo si hay o no verosimilitud del derecho o peligro en la demora; (2) para una aproximación sumaria, en cambio, estos criterios suelen adelantarse y la Corte los tiende a aplicar cuando controla la admisibilidad de la protección. Así, por ejemplo, cuando se declara inadmisible una protección interpuesta en contra de una AFP (administradora de fondos de pensiones) por alguien que quiere retirar sus fondos de capitalización individual sin haberse jubilado, lo que la Corte aplica es una concepción sumaria de la protección ya que decide en la admisibilidad y no en el fallo que ella no procede porque no se ha vulnerado la propiedad ${ }^{33}$.

Este es un aspecto que requiere un matiz adicional para intentar explicar lo que ocurre en la práctica. Lo que la jurisprudencia revela es que la aplicación del filtro de admisibilidad por parte de las Cortes de Apelaciones responde a la dualidad procesal de la protección de derechos fundamentales en un sentido aún más profundo ya que (a) se inclina hacia una concepción sumaria de su tramitación cuando se trata del criterio de la verosimilitud del derecho y (b) hacia una concepción cautelar en lo que respecta al peligro en la demora. Estos dos enfoques para decidir la admisibilidad se pueden ilustrar con algunos ejemplos.

\section{a) Verosimilitud del derecho}

A partir de su vigencia en el año 1998 se volvió más o menos habitual que las Cortes filtren una protección en base a que el derecho invocado no es "indubitado" o "preexistente" 34 con un control del escrito del recurrente que es tanto formal como de fondo ${ }^{35}$.

El adelantamiento en una decisión de este tipo no solo expresa una aproximación sumaria a la protección del art. 20 de la Constitución de 1980 sino que también traza una diferencia con otras vías judiciales que protegen derechos fundamentales en donde las exigencias para quien acude al tribunal son menores. Esto último es lo que ocurre en el procedimiento laboral de tutela de los derechos fundamentales en donde el trabajador solo debe establecer "indicios suficientes" de la vulneración (arts. 485 inciso final y 493 del Código del Trabajo) y no un derecho "indubitado" o "preexistente".

Las razones para introducir una diferencia de este tipo no pueden ser discutidas en este momento, pero resulta paradójico que un procedimiento claramente contencioso

32 Errázuriz y Otero (1989) p. 84.

33 BARRAZA CON AFP CUPRUM S.A. (2019).

34 Gómez (2005) pp. 91-93.

35 Paredes (2014) p. 134. 
como el laboral termine siendo menos exigente que una vía judicial diseñada e interpretada la mayoría de las veces por la Corte Suprema como una tutela de urgencia.

Por cierto, esta mayor exigencia cuando se recurre de protección ante una Corte también se aprecia con respecto a los derechos que no fueron incluidos expresamente en el catálogo constitucional de 1980: los llamados derechos sociales como la salud, la educación y la seguridad social ${ }^{36}$. Esto llevó a que las Cortes de Apelaciones acudiesen a estrategias polémicas para sortear la admisibilidad en favor del recurrente como la "propietarización” de su derecho ${ }^{37}$ y la equidad ${ }^{38}$.

\section{b) Peligro en la demora}

La protección es admisible cuando hay un peligro de privación, perturbación o amenaza de un derecho reconocido por el art. 20 de la Constitución de 1980. Para una concepción cautelar es suficiente con este peligro ya que de lo que se trata es de dar una respuesta judicial de urgencia. A pesar de esto, la jurisprudencia chilena también contiene casos en donde este criterio es interpretado en contra del recurrente, por ejemplo, cuando se declara inadmisible una protección por la publicación de un aviso en la entrada de un condominio que informa a los vecinos que uno de ellos no ha pagado los gastos comunes ${ }^{39}$. Decidir en la admisibilidad que estos hechos no justifican ni siquiera tramitar una protección denota una idea sumaria de la misma.

Esta volatilidad jurisprudencial exige que la dogmática procesal chilena trate de sistematizar los criterios para declarar inadmisible una protección sobre todo ante la tendencia de las Cortes de Apelaciones a acudir a un mismo criterio pero con fórmulas diversas ${ }^{40}$. Así ocurre cuando afirman que "existe otro procedimiento adecuado", "es un asunto de lato conocimiento", "tiene previsto en la ley su propio procedimiento de revisión" o "es una materia contractual que debe llevarse a la justicia ordinaria" ${ }^{41}$ todas ellas expresiones en donde lo que se invoca es un mismo criterio de admisibilidad: la protección como tutela residual ante otras instancias especializadas sin que el recurrente pueda optar entre ellas ya que no hay forum shopping.

Si bien este último es un aspecto que tampoco puede ser abordado en este artículo sí se puede recordar que el año 1992 un proyecto de ley presentado para crear tribunales contencioso administrativos incluyó la potestad de la Corte de remitir a dichos tribunales el caso que conocía por la vía de la protección, lo que implicaba reconocer que esta tutela tiene una aplicación residual en el control de la Administración del Estado (art. 63, Mensaje No 424-323).

La propia Corte Suprema ha constatado y valorado en forma negativa esta disparidad de criterios para decidir qué casos se admiten a tramitación y cuáles no. En el auto

\footnotetext{
36 Bustos (2009) pp. 233-244.

37 Vergara (1991) pp. 281-291.

38 Paillás (2002) p. 116.

39 Por todas, MARTINeZ CON CONDOMINIO PARQUe BULNes (2017).

${ }^{40}$ Un intento de sistematización de los criterios procesales de admisibilidad de la protección de derechos fundamentales en LARROUCAU (2020) pp. 5-31.

${ }^{41}$ Pinochet (2016) p. 305.
} 
acordado de 1998 reconoció "que existen criterios dispares acerca de la procedencia del recurso que eventualmente se intenta en contra de la resolución que se pronuncia sobre la inadmisibilidad de la acción de protección, ya sea que ello tenga lugar con oportunidad de la cuenta o en la sentencia que posteriormente dicte la Corte de Apelaciones". Lo que la Corte Suprema no advirtió, ni entonces ni en los autos acordados posteriores, es que esta disparidad de criterios no solo se debe a la libertad interpretativa que tienen las distintas Cortes de Apelaciones del país, sino que a la dualidad cautelar y sumaria que tensiona la tramitación de la protección del art. 20 de la Constitución de 1980 de principio a fin.

Esta dualidad en su fisonomía procesal es la que explica una situación francamente anómala: que algunas protecciones sean rechazadas tras escuchar al recurrido en su informe o en los alegatos (concepción cautelar) por las mismas razones que otras son declaradas inadmisibles de entrada (concepción sumaria). Uno de los muchos ejemplos que se pueden citar a este respecto es GONZALEZ Y OTROS CON ILUSTRE MUNICIPALIDAD DE LAS CONDES, en donde se recurrió de protección por un sistema de vigilancia con drones: allí la Cuarta Sala de la Corte de Apelaciones Santiago rechazó la protección porque no se demostró una privación, perturbación o amenaza concreta a un derecho fundamental para lo cual invocó un criterio -el de la "amenaza concreta" - que en otros casos se ha usado para declarar inadmisible la protección ${ }^{42}$.

\section{EFICACIA DE LA DECISIÓN}

La concepción cautelar de la protección de derechos fundamentales impide hablar de cosa juzgada, ya que las decisiones cautelares son órdenes judiciales provisorias. Es posible que ni siquiera tenga sentido hablar de una cosa juzgada formal ya que la resolución que ordena una medida cautelar es un auto ${ }^{43}$ y no una sentencia definitiva o una interlocutoria (art. $158 \mathrm{CPC}$ ), que son las resoluciones que producen cosa juzgada (art. $175 \mathrm{CPC}$ ).

En la literatura procesal chilena solo Hugo Pereira ha sostenido que la resolución que decide una medida cautelar es una sentencia interlocutoria de segundo grado por lo que puede producir cosa juzgada ${ }^{44}$. No obstante una interpretación como esta solo funciona cuando se trata de una medida prejudicial precautoria (art. 290 CPC) a la que sigue un juicio posterior, algo que no siempre ocurre en las protecciones ya que esta tutela puede configurar una medida cautelar anticipatoria: por ejemplo, cuando se ordena que un niño recién nacido reciba las vacunas obligatorias que sus padres se niegan a dar.

Es por ello que una aproximación cautelar a la protección conduce a que lo discutido ante una Corte se pueda plantear de nuevo en cualquier momento y sin necesidad de otros antecedentes debido a que la cosa juzgada en su efecto negativo o excluyente queda fuera de lugar ${ }^{45}$. Así, por ejemplo, en MAZA CON PROMOTORA CMR FALABELLA S.A. la Corte de Apelaciones de Santiago acogió una protección interpuesta por alguien a quien la empresa llamaba

42 Gonzalez y otros con Ilustre Municipalidad de LAS CONDES (2017).

43 Marín (2016) pp. 374-378.

44 Pereira (1997) pp. 118-120.

45 Por todas, Lebanon Investment Corporation Chile con Sauna Hermanos Ltdda. (1997) analizada en RomeRO (1999) pp. 503-515. 
todos los días para cobrar una deuda inexistente, algo que no solo fue considerado arbitrario sino que también abusivo, "pues se acosó telefónicamente a quien no tenía la calidad de deudor moroso, obligándolo a deducir dos acciones de protección por los mismos hechos, a fin de que cesara tal acoso" (cons. $\left.9^{\circ}\right)^{46}$. Como se puede ver el propio fallo estableció que el tribunal había conocido otras dos protecciones anteriores por el mismo motivo y no solo acogió la tercera protección sino que invocó en favor del recurrente su insistencia judicial como un argumento para calificar a la conducta de la empresa como abusiva.

El enfoque cautelar de la protección de derechos fundamentales exime al recurrente de invocar nuevos hechos o nuevas pruebas. En su importante trabajo del año 1982 Eduardo Soto Kloss advirtió esta posibilidad y quiso cerrarle el paso al decir que no procedería una protección "por los mismos hechos" que fundaron una anterior ya que habría cosa juzgada material ${ }^{47}$, pero no dio ningún argumento para ello de modo que su afirmación debe ser leída como una petición de principio o bien como una expresión de un enfoque sumario de la protección. Por lo que se dirá en el siguiente apartado parece que se trató de esto último ya que -al igual que la mayoría de la literatura chilena- el trabajo de Soto Kloss reconoce una concepción sumaria de la protección del art. 20 de la Constitución de 1980.

Por último, la concepción cautelar de esta tutela judicial también explica una práctica muy criticada por los abogados: la escasa -a veces nula- motivación de los fallos de protección. Esta carencia se explica porque según la ley procesal civil los autos y las sentencias interlocutorias, que es el campo en donde se mueve la técnica cautelar, solo tienen una parte considerativa cuando "la naturaleza del negocio lo permita" (art. $171 \mathrm{CPC}$ ) y son las propias Cortes las que deciden caso a caso el modo en que debe interpretarse la "naturaleza” del asunto.

\section{JUICIO SUMARIO}

La manera en que se tramita la protección de derechos fundamentales también puede interpretarse como un juicio sumario. Eduardo Soto Kloss notó de manera temprana esta posibilidad a pesar de que su trabajo suele enfatizar la importancia de la protección como una medida cautelar de urgencia. En sus palabras, "la naturaleza jurídica de la acción de protección es la de ser, en general, una acción declarativa [por lo que] el pronunciamiento cautelar es consecuencia de esa declaración de antijuridicidad del acto u omisión ilegal o arbitrario [de modo que] no es que la acción de protección sea una acción cautelar [...] lo cautelar son las medidas de protección”" ${ }^{8}$.

En los años noventa Enrique Paillás suscribió este enfoque al afirmar que la protección de derechos fundamentales es un procedimiento especial, ${ }^{49}$ algo que Jana y Marín reiteraron al calificarla como un procedimiento de urgencia similar a los interdictos posesorios ${ }^{50}$.

\footnotetext{
46 Maza con Promotora CMR FaLABELla S.A. (2017).

47 Soto (1982) pp. 293-294.

48 Sото (1982) p. 248 (destacado en el original).

49 PAillás (2002) pp. 104 y 118-119.

50 Jana y Marín (1996) pp. 86-95.
} 
La explicación procesal de este fenómeno fue articulada por Andrés Bordalí a comienzos de este siglo al identificar las razones por las cuales la protección no sería una forma de tutela cautelar sino un juicio sumario especial ${ }^{51}$. Al igual que otros procedimientos contenciosos esta tutela admite medidas cautelares como es el caso de la orden de no innovar.

De acuerdo con esta explicación la tutela judicial de derechos fundamentales no deriva del art. 20 de la Constitución de 1980 sino de su art. 19 No 3 inciso 1º, el cual contempla el derecho de acción para acudir a tribunales ${ }^{52}$. Esta tesis responde a un argumento anterior según el cual el acceso a la justicia se traduce en una única acción judicial y en múltiples pretensiones, algo que en el debate en torno a la acción se conoce como dualismo ${ }^{53}$.

$\mathrm{El}$ art. 20 de la Constitución habría establecido un "proceso especial de tutela urgente de los derechos fundamentales" 54 : un "proceso constitucional" 55.

Este es un punto pacífico en la literatura procesal chilena hoy en día. Alejandro Romero, por ejemplo, considera que "en rigor, el sistema cautelar en dicho procedimiento [protección] viene dado por la orden de no innovar, pero no por el contenido final de la sentencia [pues] solo en casos muy excepcionales se podría atribuir a la sentencia de protección naturaleza cautelar, específicamente, cuando el fallo de protección ordena adoptar medidas para conflictos que se encuentran en estado de litispendencia" ${ }^{56}$. Gonzalo Cortéz, por su parte, adhiere a la tesis de que lo cautelar en la protección de derechos fundamentales es la orden de no innovar la cual "se ha convertido en la realidad del proceso chileno como el instrumento de tutela cautelar más amplio, porque el contenido que se puede insuflar recorre la más amplia variedad de efectos cautelares conocidos" ${ }^{57}$.

En este juicio sumario especial la contradicción entre las partes se reduce al mínimo gracias al informe que debe evacuar el recurrido dentro de un plazo "breve y perentorio" tal como se ha establecido desde el auto acordado de 1977 (No 3). Esta impronta sumaria del procedimiento sugiere que las Cortes no deberían prorrogar el plazo cuando el informe no se evacua a tiempo ${ }^{58}$.

La dogmática procesal ha visto en esta solicitud del informe un equivalente del "traslado" en el juicio de lato conocimiento ${ }^{59}$ y en el informe mismo una especie de contestación de la demanda ${ }^{60}$. Este peculiar modo de formar el debate sugiere que la contradicción de partes no se difiere para un juicio declarativo posterior sino que se acota en el mismo juicio $^{61}$ y dado que la protección sería un procedimiento contencioso de cognición, la Sala

51 Bordalí (2001) p. 65.

52 Bordalí (2004) p. 274.

53 Bordalí (1999) pp. 43-58; Pinochet (2016) pp. 35-38.

54 BORDALí (2004) p. 275.

55 Bordalí (2003) p. 254 (nota 7).

56 Romero (2014) p. 170 (nota 211).

57 Cortez (2017) pp. 26-33.

58 Errázuriz y Otero (1989) pp. 157-159; Tavolari (2000) p. 517.

59 PaILlás (2002) p. 135.

60 Palomo (2009) p. 371.

61 Bordalí (2004) p. 279. 
podría tomar algunas decisiones que son propias de esta clase de juicio como llamar a conciliación a las partes ${ }^{62}$.

El mejor referente normativo de este enfoque sumario de la protección es el auto acordado del año 2015 (Acta No 94) y una práctica jurisprudencial que reúne una serie de decisiones de las Cortes que solo se explican desde el punto de vista de una tramitación sumaria. Las consecuencias procesales más significativas que se derivan de ella pueden reseñarse siguiendo la misma cronología de un juicio declarativo: debate (tribunal competente, plazo para interponer la protección, legitimación activa, participación de terceros y orden de no innovar), prueba (evidencias admisibles y valoración) y decisión (cosa juzgada y sanciones).

El análisis de cada uno de estos aspectos revela las múltiples maneras en que la protección se ha ido transformando en una instancia más de declaración de derechos, deberes y obligaciones, lo que ha relegado el rol de tutela de urgencia que motivó su creación en los años setenta.

\section{DeBATE}

\section{a) Tribunal competente}

La competencia para conocer de la protección de derechos fundamentales fue entregada desde un inicio a la Corte de Apelaciones respectiva (art. 20 inciso $1^{\circ}$ de la Constitución de 1980).

Esta regulación ha sido modificada por medio de autos acordados solo como una respuesta a la sobrecarga de trabajo de la Corte Suprema y de la Corte de Apelaciones Santiago, en este último caso debido al profuso empleo de la protección en contra de la Administración del Estado, lo que afectó a dicho tribunal ya que la mayoría de los servicios públicos recurridos se encuentran en Santiago.

Para hacer frente a esta sobrecarga de trabajo la Corte Suprema incluso llegó a distribuir -en el auto acordado de 1998- la competencia de las apelaciones de las protecciones entre sus Salas de acuerdo con un criterio geográfico ${ }^{63}$. Este reparto fue criticado por incrementar las probabilidades de un trato desigual por parte de las Salas de la Corte Suprema ${ }^{64}$.

En el año 2015 la Corte Suprema tomó una medida específica para descongestionar a la Corte de Apelaciones de Santiago al darle competencia a la Corte de Apelaciones del lugar en donde se hubiere "cometido el acto o incurrido en la omisión" que causa privación, perturbación o amenaza del derecho o bien a la del lugar en que se producen los efectos, a elección del recurrente (No 1, Acta No 94).

A pesar de estos cambios la regulación de la competencia es incompleta ya que da lugar a ciertas dudas que han debido ser abordadas por los propios tribunales. Así, por ejemplo, si alguien es afectado por varios actos de personas domiciliadas en diversos territorios

\footnotetext{
62 Cerda (2001) p. 398.

63 Primera Sala (Civil) (Temuco, Valdivia, Puerto Montt, Coyhaique y Punta Arenas), Segunda Sala (Penal) (Arica, Iquique, Copiapó, La Serena, Antofagasta y Valparaíso) y Tercera Sala (Constitucional) (Santiago, San Miguel, Rancagua, Talca, Chillán y Concepción).

${ }^{64}$ Bordalí (2007) p. 54.
} 
jurisdiccionales se ha discutido si quien recurre puede escoger la Corte de Apelaciones ante la cual interpone la protección (i. e., si es posible autorizar el forum shopping) ${ }^{65}$.

Este es un buen momento para recordar una de las consecuencias procesales de la tesis radical de Errázuriz y Otero en cuanto al art. 20 de la Constitución de 1980. De acuerdo con su lectura la protección no permitiría la prórroga de competencia del recurrido ya que ella es una vía judicial inquisitiva y unilateral de modo que no hay contraparte y, de haberla, sería la propia Corte de Apelaciones la cual no podría excusarse de conocer el caso (art. 10 inciso 2 COT). Una consecuencia que se deriva de esta falta de prórroga es que la protección se podría interponer ante cualquiera de las Cortes de Apelaciones del país (art. 187 No 1 COT) ${ }^{66}$.

\section{b) Plazo}

El plazo original para recurrir de protección de derechos fundamentales fue de quince días (No 1, auto acordado de 1977) el que se amplió tres décadas más tarde a treinta días (auto acordado de 2007).

La existencia misma de un plazo para recurrir ha sido cuestionada porque sería una especie de caducidad del derecho fundamental ${ }^{67}$. Es por esto que se ha sugerido que la protección no debería tener un plazo y, en caso de haber uno, no tendría que ser inferior a seis meses ${ }^{68}$.

En este caso se trata de un plazo de días "corridos" (i. e., discontinuo si se aplica estrictamente el art. 66 CPC) cuyo inicio se cuenta "desde la ejecución del acto o la ocurrencia de la omisión (sic) o, según la naturaleza de estos, desde que se haya tenido noticias o conocimiento cierto de los mismos" (No 1 Acta No 94 de 2015). Así, por ejemplo, en Korol con Bío-Bí Comunicaciones S.A. y otros la Segunda Sala de la Corte de Apelaciones de Santiago rechazó por extemporánea la protección que interpuso un abogado con el fin de que se eliminase una noticia sobre una estafa que hizo a unos clientes porque se entendió que hacía varios años que este abogado sabía de la existencia de la noticia por la cual recurrió ${ }^{69}$.

A pesar de la claridad de esta regla la forma de contar el inicio del plazo ha sido discutida cuando se trata de actos administrativos que admiten recursos ante la propia Administración o bien cuando se trata de actuaciones compuestas por una serie de actos intermedios. Para estos escenarios se ha propuesto usar el criterio objetivo de la ejecución, es decir, que el cómputo el plazo para recurrir se inicie una vez agotados dichos recursos o actos ${ }^{70}$.

La ley señala que el debate en sede administrativa interrumpe el plazo para recurrir de protección (art. 54, Ley No 19.880 del año 2003). Esto implica que si el interesado pierde en sede administrativa lo más probable es que el plazo para recurrir de protección

65 Rol No 21.034 citada en Soto (1985) p. 190.

66 Errázuriz y Otero (1989) pp. 89-90.

67 SCHIESSLER (1982) p. 358.

68 PinOCHet (2016) pp. 311-314.

69 Korol con Bío-BIo Comunicaciones S.A. y OtRos (2017).

70 Gómez (2005) p. 126; Pinochet (2016) pp. 315-317. 
haya caducado, pues se entenderá que nunca fue interrumpido. De allí que hubiese sido preferible que la ley considerase que el inicio del debate administrativo suspende dicho plazo en lugar de interrumpirlo.

En el caso de las omisiones de un servicio público que no está obligado a actuar dentro de un término específico Eduardo Soto Kloss propuso una idea aún más polémica: que el inicio del plazo para recurrir de protección lo fije prudencialmente la propia Corte de Apelaciones ${ }^{71}$.

\section{c) Legitimación activa}

La dualidad cautelar y sumaria de la protección de derechos fundamentales tiene un impacto considerable durante la fase de debate. Esto se puede ver en relación con la legitimación para recurrir y con otras nociones que son aledañas a este elemento constitutivo de la acción como la exigencia de capacidad para comparecer cuando quien recurre es un tercero.

En relación con esto último la exigencia de capacidad para comparecer a juicio cuando quien recurre es un tercero -algo que existe desde el auto acordado de 1977 (No 2)- ha sido ampliamente cuestionada porque el art. 20 de la Constitución no precisa tal capacidad ${ }^{72}$.

Lo mismo se puede decir del debate respecto de si este tercero -quien actúa como un agente oficioso- puede o no desistirse de la protección. Esta posibilidad ha sido rechazada con un argumento que es típico de un juicio contencioso: el poder de disposición del tercero se agotaría en el solo hecho de interponer ante la Corte de Apelaciones una protección a nombre de otro ${ }^{73}$.

En este mismo plano cabe destacar la práctica judicial de permitir las adhesiones a la protección lo cual ha sido visto como una especie de litisconsorcio activo para evitar decisiones contradictorias ${ }^{74}$.

En otras palabras, tanto la capacidad para comparecer a juicio del tercero, como el debate en torno a su desistimiento y a la adhesión a la protección revelan una concepción sumaria de la misma.

La aproximación cautelar reaparece cuando se analiza la legitimación activa ya que en este aspecto las Cortes han cultivado una interpretación laxa que es propia de la tutela cautelar de urgencia. Así, por ejemplo, en CONSEJO DE AUtORIDADES ANCESTRALES DEL PUEblo Nación Mapuche "Nisol GNulam" con Dirección General de TerRitorio Marítimo Y MARINA MERCANTE DE LA ARMADA DE CHILE, se interpuso una protección en contra de la autorización para verter más de nueve mil toneladas de salmones muertos a ciento cuarenta kilómetros de la costa de Chiloé esgrimiendo la "propiedad que el Pueblo Nación Mapuche posee sobre el mar" un fundamento objetado por la recurrida pero que la Corte de Apelaciones de Valparaíso no cuestionó al momento de decidir el caso (cons. $7^{75}$ ).

\footnotetext{
Soto (1982) p. 264.

72 Pinochet (2016) p. 154.

73 SCHIESSLER (1982) p. 361

74 Soto (1982) pp. 265-267.

75 Consejo de Autoridades Ancestrales del Pueblo Nación Mapuche "ÑIsol Gnulam" con Dirección General de Territorio Maritimo y Marina Mercante de la Armada de Chile (2016).
} 
En esta misma línea la jurisprudencia ha reconocido una amplia legitimación activa para recurrir de protección tanto en el caso de particulares (por ejemplo, en PHILIPPI y OtRos CON LABORATORIo CHILE S.A. se aceptó la legitimación para recurrir al concebido no nacido respecto de un anticonceptivo de emergencia ${ }^{76}$ ) como a los órganos de la Administración del Estado. En este último caso la jurisprudencia ha aceptado la idea de que "un ente público personificado puede ser lesionado en su esfera "subjetiva» (si cupiera con precisión el adjetivo" 77 : por ejemplo, al aceptar que unos municipios recurriesen en contra de la Contraloría General de la República respecto del cobro de una patente a ciertas sociedades de inversión ${ }^{78}$.

\section{d) Participación de terceros}

El enfoque cautelar limita la intervención de los terceros durante la tramitación de una protección a la categoría de tercero excluyente, algo que no ocurre en la aproximación sumaria. Esto queda de manifiesto en la regla que señala que al apelarse una protección el Presidente de la Corte Suprema puede ordenar dar cuenta preferente en la Sala que corresponda y que la protección sea resuelta previa vista de la causa, la que se agrega extraordinariamente a la tabla respectiva de la Sala (1) si lo estima conveniente, (2) se le solicita con fundamento plausible y (3) especialmente cuando se le pide de común acuerdo por recurrente, recurrido y quienes hayan sido considerados como partes en el procedimiento (No 7, Acta No 94 de 2015).

Esta misma forma de entender la participación de los terceros en las protecciones se observa a partir de los años noventa cuando la protección intensificó su campo de aplicación hacia el control de actuaciones de particulares ${ }^{79}$. Así, por ejemplo, en el año 1993 en el famoso caso LuKSIC con MARTORELl y EDITORIAL Planeta donde el recurrente afirmó que el libro en cuestión era una "basura moral que nadie puede aceptar sin lesionar los valores fundamentales en que descansa la sociedad cristiana occidental" (cons. $1^{0^{80}}$ ) compareció entre otros "Marco Antonio Enríquez Gumucio, cineasta, estudiante de la Universidad de Chile" como tercero coadyuvante para alegar que se trataba de un caso de censura previa y pedir que se dejase sin efecto la prohibición de vender el libro Impunidad diplomática (cons. 5º).

En TOLEDO CON AGUILERA ${ }^{81}$ también se advierte una actuación como tercero coadyuvante típica de un procedimiento contencioso. En este caso la jueza recurrida de protección fue apoyada por alguien que litigaba otro juicio ante el Juzgado de Letras del Trabajo de Talca a cargo de la misma jueza. Esta circunstancia originó más adelante un incidente de

\footnotetext{
76 Philippi y otros con Laboratorio Chile S.A. (2001).

77 Soto (1982) p. 73.

78 Municipalidades de Santiago y otras con Contraloría General de la República (2012) analizada en LeWIS (2013) pp. 129-141.

79 Larroucau (2019a) pp. 261-263.

80 LuKsic con Martorell y EDitorial Planeta (1993).

81 Toledo con Aguilera, Corte de Talca, Rol No 2633-17, citado en VALDIVIA CON CORPORACIÓN DE AsistenCIA Judicial DE LA REGión MEtropolitana (2017) visto y cons. $1^{\circ}$.
} 
recusación en contra de la magistrada -VALDIVIA CON CORPORACIÓN DE ASISTENCIA JUDICIAL DE LA REGIÓN METROPOLITANA- el que fue rechazado por la Corte de Apelaciones de Talca ${ }^{82}$.

Las formas de participación de los terceros y el modo en que se comparece ante la Corte son dos aspectos más en donde la dualidad cautelar y sumaria de la protección marca una diferencia significativa. En cuanto a la forma de comparecer ante la Corte las contradicciones surgen porque el art. 4 del Acta No 94 de 2015 señala que "las personas, funcionarios u Órganos del Estado afectados o recurridos, podrán hacerse parte en el recurso” lo que da a entender que el solo hecho de haber sido recurrido no les hace parte, ni a los terceros ("afectados"), ni a la contraparte ("recurridos").

Para aclarar este punto dicha regla puede ser interpretada en relación con la Ley No 20.886 del mismo año 2015, ya que en la tramitación electrónica se eliminó la carga de comparecer en segunda instancia -algo que la parte tenía que cumplir dentro del plazo de cinco días- y se impuso en su lugar un deber del propio tribunal de emplazar a las partes. Este deber del tribunal se cumple cuando la Corte certifica en la carpeta electrónica la comunicación del tribunal de primera instancia en cuanto a que el recurso de apelación fue declarado admisible (arts. 197, 200 y 800 No 1 CPC). Este cambio demuestra que en algunos casos el derecho de defensa de las partes puede ser resguardado sin que sea necesario imponer una carga o un deber a las partes lo que es relevante a la hora de interpretar el principio de buena fe procesal.

\section{e) Orden de no innovar}

Para una concepción sumaria de la protección su dimensión cautelar se expresa fundamentalmente en la orden de no innovar (ONI). La ONI tiene un importante efecto por cuanto radica la causa en la Sala que la ordena. Esto abre una discusión cuando se acumulan en una misma Sala varias protecciones que cuentan con ONI. En una situación como esta el Pleno de la Corte de Apelaciones de Santiago resolvió que la protección debía ser conocida por la Sala que primero dictó una ONI, algo que llevó a sugerir su radicación en la Sala que sorteó el Presidente de la Corte para evitar que su tramitación se dilate pidiendo el cumplimiento de una gestión ${ }^{83}$.

En el ámbito de una concepción cautelar, en cambio, la ONI no tendría sentido porque se trataría de una medida cautelar dentro de una técnica que en sí misma es cautelar, a menos que se la concibiera de un modo trivial como una medida cautelar nominada en un universo de medidas cautelares innominadas; algo así como un "instrumento del instrumento" cautelar de la protección en una analogía con la suspensión del amparo mexicano ${ }^{84}$.

Es por esto que la concepción sumaria del art. 20 de la Constitución de 1980 permite comprender mejor el rol de la ONI, pues quien recurre busca una tutela rápida de modo que una vez identificado el objeto procesal lo que debe hacer la Corte es adoptar las medidas que correspondan para evitar un daño.

\footnotetext{
82 VAldivia con Corporación de Asistencia Judicial de LA REGión MEtropolitana (2017).

83 Errázuriz y Otero (1989) pp. 180-182.

84 Tavolari (1994) pp. 158-168.
} 
La ONI puede tener el carácter de una medida cautelar innovativa cuando "se anticipa a la sentencia definitiva" ${ }^{5}$-también llamada, con una fórmula redundante, una "cautela innovativa de innovar" (sic $)^{86}$ - tal como ocurre en los casos en que la Corte ordena una transfusión de sangre ${ }^{87}$.

Por último, la discusión en torno a si la ONI debe motivarse o no se conecta nuevamente con la calificación jurídica de la resolución judicial que decide una protección ya que en este caso puede tratarse de un auto ${ }^{88}$ o de una interlocutoria (art. 158 CPC) de modo que su motivación depende de su "naturaleza" (art. 171 CPC) a juicio de la Corte respectiva.

\section{PRUEBA}

A pesar de que el texto constitucional de 1980 y los autos acordados casi no contienen menciones a la prueba esta fase de los procedimientos contenciosos está muy presente en la práctica. En palabras de Raúl Tavolari los "tribunales y litigantes han ido conformando un verdadero estatuto jurídico de facto de la prueba, ante la insuficiente normativa evidente" 89 .

En un comienzo solo se contempló la posibilidad de que la Corte pueda "para mejor acierto del fallo, decretar todas las diligencias que estime necesarias para el esclarecimiento de los hechos" (No 3, auto acordado de 1977). Para ello se hizo una referencia a la categoría genérica de "antecedentes" la cual ha sido interpretada como "una especie de simbiosis" de todos los medios de prueba de la ley procesal civil ${ }^{10}$.

Esta carencia de reglas específicas en el ámbito probatorio ha ocasionado varios debates cuando la protección se concibe desde el punto de vista sumario. Por ejemplo, alguna vez se sostuvo -por analogía con el sumario del Código de Procedimiento Penal del año 1906que los instrumentos no requerían ser acompañados con citación ${ }^{91}$, algo que ya en 1982 fue criticado por Eduardo Soto Kloss dado que la práctica de tener por acompañados los instrumentos para su sola vista (ad effectus videndi) sin dar la posibilidad de contradecirlos dejaba sin efecto el mecanismo contemplado por ley procesal civil para resguardar el derecho de defensa ante una Corte que sí debe valorar estos instrumentos (art. 348 inciso 2 CPC) ${ }^{92}$.

En cuanto a la valoración de la prueba en particular el autor acordado de 1977 dispuso que estos antecedentes se apreciasen en conciencia (No 7). Este modelo dio paso a una valoración según la sana crítica en el auto acordado de 1998 ( No 5) lo que trajo consigo un ingreso de todas las discusiones que son propias de este sistema de valoración en la protección de derechos fundamentales. Así, por ejemplo, en VÁSQUEZ CON UNIVERSIDAD ACADEMIA HuMANismo CRISTIANO un estudiante recurrió de protección porque se le exigía acreditar experiencia laboral para rendir el examen de grado en un programa especial de

\footnotetext{
85 ZúNiga (1997) p. 112.

86 GÓmez (2005) p. 273 (nota 448).

87 Pinochet (2016) pp. 383-390.

88 Oberg (1987) p. 60.

89 Tavolari (2000) p. 512.

90 Pinochet (2016) p. 406.

91 Errázuriz y Otero (1989) p. 163.

92 Soто (1982) pp. 367-369.
} 
titulación en derecho, la que fue acogida por la Corte de Apelaciones de Talca por una infracción a la sana crítica, puesto que "pugna con la lógica y las máximas de la experiencia, como elementos integrantes de la sana crítica, que un estudiante pueda adquirir la calidad de egresado de una carrera universitaria y obtener un certificado oficial emitido por la Universidad respectiva, sin haber cumplido previamente con la totalidad de los requisitos curriculares previstos en su plan de formación" (cons. $\left.8^{\circ}\right)^{93}$.

La importancia de la fase probatoria en las protecciones es una consecuencia de su concepción como procedimiento declarativo sumario. Esto se aprecia no solo en el detalle con el cual las Cortes pueden llegar a describir los hechos en sus fallos sino que también en la cantidad de evidencias que se rinden ante ellas. Esto último salta a la vista, por ejemplo, en un caso como JEREZ CON ASOCIACIÓN CHILENA DE SEGURIDAD en donde se recurrió debido al alza médica que se ordenó respecto de un reposo laboral luego de que se cambiase un diagnóstico de depresión por uno de trastorno adaptativo lo que llevó a que el trabajador terminase siendo despedido por una ausencia injustificada de su lugar de trabajo. La Corte de Apelaciones de Concepción acogió la protección luego de valorar una serie de evidencias relacionadas con la forma en que se diagnosticó al trabajador entre las que se incluían su ficha clínica, los informes de varios médicos y la atención que le brindó la Asociación Chilena de Seguridad ${ }^{94}$.

Por el contrario, cuando no se abre una fase probatoria en la tramitación de la protección lo que se reivindica es su rol de tutela cautelar de urgencia. Un ejemplo en este último enfoque es el caso Vergara y Morales con SuperintendenCia de MEDio Ambiente V ReGión en donde se recurrió invocando como un hecho público y notorio en base a una nota de prensa de El Mostrador el exceso de metales pesados en las comunas de Puchuncaví y Quintero ante lo cual la Corte de Apelaciones de Valparaíso rechazó la protección porque no se trataba de "hechos indubitados" sino que de circunstancias que requerían de "una indispensable y completa prueba pericial con la que aquí no se cuenta" (cons. $2^{\circ}$ ) y es el caso que en una protección "no puede ahondarse en actividades probatorias complejas" (cons. 10)95.

Por último, la inclusión de la sana crítica en el año 1998 también dio pie a disputas entre las Cortes de Apelaciones y la Corte Suprema en torno a los hechos que se deben tener por probados. Esta posibilidad es típica de un procedimiento judicial contencioso. Así, por ejemplo, en Conejera con Hospital Clínico de la UNIVERSIDAd de Chile un clásico caso de protección en Chile -a propósito de la exigencia de un cheque en garantía a los familiares para atender al paciente- la Corte de Apelaciones de Santiago rechazó la protección con el argumento cautelar de que ella "no tiene elementos de juicio suficientes que puedan otorgarle certeza que los cheques fueron entregados contra la voluntad del recurrente, por cuanto no es esta sede en la que estos sentenciadores puedan apreciar u objetar el valor probatorio de la constancia de entrega de documentos antes señalada, máxime si es controvertida" ${ }^{16}$ y la Corte Suprema confirmó esta decisión porque la recurrente no

\footnotetext{
93 VASQUEZ CON UNIVERSIDAD ACADEMIA HUMANISMO CRISTIANO (2016).

94 JEREZ CON ASOCIACIÓN CHILENA DE SEGURIDAD (2017).

95 Vergara y Morales con SuperintendenCIa de MEDio Ambiente V REGión (2015).

96 JEREZ CON ASOCIACIÓN ChILENA DE SEGURIDAD (2017).
} 
cuestionó la deuda con el hospital en su apelación dado que ya estaba pagada, pero el fallo tuvo un voto en contra que rescató la concepción sumaria de la protección. De acuerdo con este voto en contra firmado por el Ministro Sergio Muñoz el caso reunía los elementos de juicio suficientes como para concluir que los antecedentes que tuvo a la vista la Corte de Apelaciones de Santiago bastaban para tener por probado que la entrega de los cheques no fue voluntaria ${ }^{97}$.

\section{DECISIÓN}

\section{a) Cosa juzgada}

A diferencia de la concepción cautelar la aproximación sumaria califica al fallo de protección como una sentencia definitiva ${ }^{98}$. Esto permite hablar de cosa juzgada aunque los efectos de la misma no sean del todo claros.

El primer paso en este campo es advertir que lo resuelto por la Corte se presume verdadero en un nuevo juicio entre las mismas partes (art. 427 inciso 2 CPC). Esta regla es un fundamento suficiente para sostener que el control judicial de la legalidad o arbitrariedad de una conducta a través de la protección del art. 20 de la Constitución de 1980 implica que "la declaración de culpabilidad constituye un juicio de antijuridicidad permanente, pues ella está referida a los principios que regulan la conducta en sociedad"99.

Esta permanencia de lo resuelto ha hecho que la protección sea un espacio idóneo para las declaraciones de mera certeza ${ }^{100}$, puesto que el fallo disipa la incertidumbre respecto de si una acción u omisión es ilegal y/o arbitraria ${ }^{101}$. Esto explicaría también el hecho de que las Cortes generalmente no requieran de un modelo de ejecución para cumplir con los fallos de protección ya que las declaraciones de mera certeza no se ejecutan sino que solo precisan de órdenes para su cumplimiento ${ }^{102}$.

En lo que se refiere estrictamente al efecto de cosa juzgada hay opiniones divididas en cuanto a su extensión mas no así en cuanto a su procedencia. Si bien la mayor parte de la dogmática chilena considera que el fallo solo produce un efecto de cosa juzgada formal hay algunos matices que se deben tener en cuenta ${ }^{103}$.

Raúl Tavolari considera que este efecto dependerá de si se acoge o rechaza la protección: (a) si se rechaza la persona puede acudir de nuevo a tribunales pero (b) si se acoge el recurrido no puede desafiar la orden judicial porque solo el titular del derecho afectado puede acudir a otras vías judiciales y, además, porque si este fallo no produjera cosa juzgada

97 Conejera con Hospital Clínico de la Universidad de Chile (2017).

98 Errázuriz y Otero (1989) p. 190; Palomo (2009) p. 374.

99 Dougnac (2001) p. 619 (destacado en el original).

100 Tavolari (2000) pp. 464-465; Paillás (2002) pp. 118-119.

101 Errázuriz y Otero (1989) p. 202.

102 Rivero (2019) p. 119.

103 Romero (2002) pp. 136-143, Bordalí (2019) p. 252. 
material se daría "el insólito fenómeno" de que un tribunal "inferior" podría revertir la decisión de uno "superior" 104 .

Priscila Machado suma una variable diferente al resultado del juicio al destacar la conexión entre el incremento de la prueba en las protecciones y el efecto de cosa juzgada material de los fallos ya que si la cosa juzgada se limita solo a los hechos decididos (res iudicata) ello es porque efectivamente hubo hechos que fueron debatidos y probados (res iudicanda) ${ }^{105}$. Este enfoque le permite concluir que también habría un efecto de cosa juzgada material en el fallo que rechaza la protección cuando se basa en prueba documental suficiente ${ }^{106}$.

En el campo específico de la Administración del Estado, Eduardo Soto Kloss tomó nota de otro factor -diverso al resultado del juicio y a la prueba rendida- y que tiene que ver con aquel en contra de quien se recurre. Desde este punto de vista si se recurre en contra de un órgano público el fallo produce cosa juzgada material en dos escenarios: cuando se ordena la nulidad de un acto administrativo y también cuando se declara que una omisión administrativa es ilegal o arbitraria ${ }^{107}$.

En el plano de las decisiones administrativas también cabe destacar el uso de la prohibición de ir contra acto propio - una infracción típica de la buena fe procesal- para conseguir el mismo efecto de la cosa juzgada material: evitar que los órganos públicos cambien de opinión y defrauden la confianza legítima de la persona que tomó decisiones en base a lo resuelto por aquellos. Así, por ejemplo, si una Dirección de Obras Municipales ordena paralizar una construcción que ella misma autorizó se ha resuelto en favor de la protección, ya que este cambio defrauda las expectativas de quien inició las faenas tomando en cuenta la autorización inicial ${ }^{108}$.

Por último, la posibilidad de hablar de cosa juzgada material en la protección que acarrea la concepción sumaria tiene otras consecuencias procesales que son relevantes. Aquí se pueden mencionar dos: es un argumento que fortalece la idea de que la protección puede operar como un sucedáneo de un procedimiento contencioso administrativo en la justicia chilena ${ }^{109}$ y permite criticar el hecho de que los fallos de protección se limiten a su parte resolutiva sin incluir una motivación completa de los aspectos fácticos y jurídicos del caso (art. 170 No 4 y 5 CPC) ${ }^{110}$.

\section{b) Sanciones}

El diseño cautelar de la protección del art. 20 de la Constitución de 1980 solo contempló un aparato sancionatorio mínimo en relación con los antecedentes necesarios para tomar una decisión. En este sentido la Corte puede sancionar a quien no evacúa el informe requerido con las mismas medidas que la ley orgánica le otorga al juez para que ejerza un

104 TaVolari (2000) pp. 526-529 (nota 667).

105 Machado (2019) pp. 754-760.

106 Machado (2019) p. 760.

107 Soto (1984) pp. 7-8; Pinochet (2016) p. 419.

108 Domínguez (1992) pp. 76-79.

109 ZúNiga (1997) p. 109.

110 Paredes (2014) pp. 151-158. 
control disciplinario ante las faltas o abusos cometidos en un juicio ( $\mathrm{N}^{\circ} 12$, auto acordado de 1977): (1) amonestación privada, (2) censura por escrito, (3) pago de las costas, (4) multa o (5) suspensión de funciones hasta por cuatro meses con goce de medio sueldo (art. 537 COT).

El Tribunal Constitucional no ha estimado inconstitucional el hecho de que estas sanciones se fijen en un auto acordado ${ }^{111}$.

En el año 1992 se produjo un pequeño giro hacia la concepción sumaria en este ámbito cuando el auto acordado incorporó expresamente la posibilidad de una condena en costas "cuando lo estimen procedente" las Cortes (No 11). En relación con esta regla Lautaro Ríos propuso hacer uso de la siguiente distinción: (a) que la condena en costas en favor de quien recurre proceda cuando la protección se acoge por una afectación del derecho "claramente" injustificada, porque el acto era "manifiestamente" contrario a derecho y "siempre" en segunda instancia si se revoca una sentencia desfavorable en primera instancia; y (b) que la condena en costas recaiga sobre el recurrente cuando era "manifiesto" que la protección carecía de un fundamento razonable o bien era "evidente" que sus fines fueron "pervertidos" como ocurriría, por ejemplo, si se la usa solo para obtener información o para amedrentar a alguien ${ }^{112}$.

El problema de las costas en las protecciones ha sido discutido con algo más de atención a propósito de las condenas que afectan a empresas que venden seguros médicos (Isapres) y en contra de las que se recurre usualmente porque aumentan de manera unilateral el precio del plan de salud. En el año 2015 la Corte de Apelaciones de Santiago fijó una suma única para estas costas la cual fue menor a la mitad de la que ella misma había establecido antes para estos casos "sea que los abogados patrocinantes hagan o no uso de su derecho a alegar" (Rol No 1263-2015). No es una sorpresa que los requerimientos para que el Tribunal Constitucional declare la inconstitucionalidad de estas regulaciones de las costas a través de autos acordados tampoco hayan sido acogidos ${ }^{113}$.

En cuanto al cobro de las costas la concepción sumaria de la protección disipa todo tipo de dudas en cuanto a que la propia Corte que las impone tiene competencia para su ejecución (arts. 111, 113 y 114 COT).

Finalmente, cabe agregar que Enrique Paillás propuso aplicar algo similar a las astreintes francesas como un incentivo para asegurar el cumplimiento de lo que ordenen las Cortes al acoger una protección cuyos fundamentos serían el imperio judicial (art. 11 COT) y la equidad ${ }^{114}$.

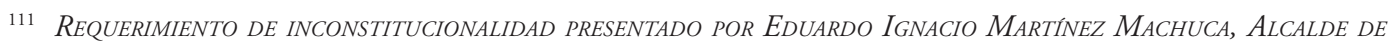

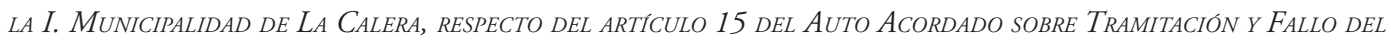
Recurso de Protección de las Garantias Constitucionales de la Corte Suprema (2013), analizada en Parodi (2014) pp. 283-296.

112 Ríos (1994) pp. 55-56.

113 REQUERIMIENTO POR INCONSTITUCIONALIDAD DE ISAPRE CRUZ BLANCA S.A. RESPECTO DEL APARTADO $11^{\circ}$ DEL AUTO ACORDADO SOBRE TRAMITACIÓN Y FALLO DEL RECURSO DE PROTECCIÓN (2011), analizada en SALAS (2011) pp. 417-427 y ZÚNIIGa (2011) pp. 404-411.

114 Paillás (2002) pp. 125-128.
} 


\section{LAS INCONSISTENCIAS PROCESALES ENTRE EL TEXTO CONSTITUCIONAL DE 1980 (CAUTELAR), LA REGULACIÓN MEDIANTE AUTOS ACORDADOS (SUMARIA) Y LA LEY PROCESAL CIVIL (SUPLETORIA)}

Las reglas de los autos acordados de la Corte Suprema han alterado el objetivo inicial de la protección como tutela de urgencia al darle la fisonomía de un juicio sumario. Una posible explicación para ello puede encontrarse en la tensión general aludida en un comienzo en cuanto a que el derecho de acceso a la justicia de quien pide la tutela de un derecho fundamental ha tratado de ser equilibrada con el derecho a un debido proceso que tiene aquel en contra de quien se recurre. Pero esta búsqueda de un punto medio a través de autos acordados no ha sido exitosa.

Junto con los aspectos que ya fueron analizados en las secciones anteriores esta dualidad cautelar y sumaria de la protección del art. 20 de la Constitución de 1980 tiene un ingrediente más en la aplicación supletoria de la ley procesal civil de 1903. Entre las principales incongruencias procesales que se derivan de esta mezcla de fuentes cabe resaltar los siguientes cinco aspectos.

Primero, lo que dispuso el texto constitucional de 1980, en cuanto a que la Corte adopte "de inmediato" las medidas necesarias para restablecer el derecho afectado, perdió fuerza debido a una actuación procesal dispuesta por la Corte Suprema previamente en el auto acordado de 1977: dictar un decreto ("autos en relación") y agregar en tabla la causa de forma extraordinaria (No 3).

Segundo, aunque la Constitución de 1980 no contempló una apelación ante la Corte Suprema de lo resuelto por la Corte de Apelaciones todos los autos acordados han incluido dicha posibilidad y solo en el año 1990 la ley orgánica de los tribunales reconoció esta apelación (art. 98 No 4 COT reformado por la Ley No 18.969).

Tercero, si bien para la concepción sumaria el fallo de la Corte es una sentencia definitiva el auto acordado de 1992 dispuso que el plazo para apelarla es de cinco días -lo que amplió el plazo original de 24 horas- a menos que se trate de ciertos derechos fundamentales (art. 19 No 1, 3 inciso 4, 12 y 13 de la Constitución) en donde el plazo es incluso menor: dos días. La extensión de estos plazos contrasta con el término general para apelar una sentencia definitiva de diez días que consigna la ley procesal civil (art. 189 inciso 2 CPC).

Cuarto, a pesar de su calidad de sentencia definitiva de acuerdo con la concepción sumaria quien apela debe pedir alegar en base a un fundamento plausible ya que de lo contrario el recurso se decide en cuenta. El Tribunal Constitucional tampoco ha cuestionado esta forma de conocer la apelación en la protección de derechos fundamentales (TOBAR CON ISAPRE CRUZ BLANCA S.A., cons. $23^{\circ}$ y $39^{115}$ ). Este diseño también difiere de ley procesal civil en donde solo se piden alegatos cuando se apela de resoluciones judiciales diversas a la sentencia definitiva (art. 199 inciso $1^{\circ} \mathrm{CPC}$ ) y, tratándose de estas últimas, en algunas situaciones especiales como la ley de pesca y acuicultura que requiere "motivos fundados" (art. 93 a. No 15, Ley No 18.892 del año 1989).

115 TOBAR CON ISAPRE CRUZ BLANCA S.A. (2011). 
Quinto, la suspensión de la vista de la causa a petición de la recurrida solo procede si la Corte la considera "muy calificada" (No 6, auto acordado de 1977) y nunca por acuerdo entre las partes (No 9, Acta No 94), a diferencia de lo que dispone la ley procesal civil (art. 165 No 5 CPC).

Hay también otras diferencias procesales que desaparecieron debido a los cambios que han hecho estos mismos autos acordados de la Corte Suprema. Así, por ejemplo, hasta el año 1998 no se exigió que la apelación de la protección fuese un recurso fundado tal como lo requiere la ley procesal civil (art. 189 inciso $1^{\circ} \mathrm{CPC}$ ), aunque no se trata de una apelación subsidiaria de una reposición ni de un procedimiento oral, que son los dos escenarios en donde se exime de esta exigencia de fundar el recurso o bien se la reduce a una fundamentación somera (art. 189 inciso 3 CPC).

Los cinco aspectos anteriores se suman entonces a los mencionados en las secciones previas y dan cuenta de divergencias que son lo suficientemente significativas entre el texto constitucional de 1980, los autos acordados de la Corte Suprema y la ley procesal civil supletoria en cuanto a la tramitación de esta tutela judicial como para concluir que ellas deben zanjarse mediante una reforma legal. La envergadura de estas diferencias impide que sea el mismo Pleno de la Corte Suprema quien las resuelva como propusiera Eduardo Soto Kloss $^{116}$. Es necesario que el Congreso se pronuncie al respecto.

Solo una vez que las Cortes chilenas cuenten con una fisonomía normativa clara y coherente para la tramitación de esta tutela judicial podrán cumplir el rol activo de prevención, corrección y sanción de aquellas conductas que obstaculicen el debate tal como lo ordena el principio de buena fe procesal (art. 2, Ley No 20.886 de 2015). La última sección de este artículo analiza el modo en que el debate en torno al proyecto del año 2001 ha abordado este desafío ${ }^{117}$.

\section{EL PROYECTO DEL AÑO 2001 PARA REGULAR LEGALMENTE LA TRAMITACIÓN DE LA PROTECCIÓN}

El sistema jurídico chileno tiene que cumplir con una exigencia que proviene de tratados internacionales en cuanto a contar con "un procedimiento sencillo y breve" respecto de los "actos de autoridad" que violen los derechos fundamentales (art. 8, Declaración Universal de los Derechos y Deberes del Hombre del año 1948) o, en palabras ligeramente diversas, "un recurso sencillo y rápido o cualquier otro recurso efectivo" en contra de "actos" que afecten estos derechos fundamentales (art. 25 No 1, Convención Americana sobre Derechos Humanos del año 1969).

En el año 2001 un grupo de diputados presentó al Congreso un proyecto de ley con el fin de "desarrollar exhaustivamente" las "acciones constitucionales de amparo o habeas corpus y protección” (Boletín No 2809-07). Este proyecto puso énfasis en los aspectos constitu-

\footnotetext{
116 Soto (1982) p. 302.

117 En el año 1998 (Boletín No 2191-07) y en el año 2005 (Boletín No 4011-07) se presentaron otros proyectos de ley para regular la tramitación de la protección de derechos fundamentales los cuales no prosperaron en el Congreso y también fueron informados de forma negativa por la Corte Suprema, en Oficio No 1.749 (octubre de 1998) y Oficio No 101 (agosto de 2006) respectivamente.
} 
cionales del problema, pero poco o nada avanzó desde una óptica procesal. El debate en este último plano tampoco ha ido muy lejos ya que se han sugerido cambios profundos como eliminar los "presupuestos procesales" de la ilegalidad o arbitrariedad del acto u omisión para "consolidar un control de constitucionalidad lo más puro posible"118 o crear una "nueva acción constitucional" que opere de modo residual directamente ante el Tribunal Constitucional ${ }^{119}$, pero ninguna de estas propuestas se ha detenido a tomar en cuenta las inconsistencias procesales que afectan a la protección del art. 20 de la Constitución de 1980.

El proyecto de 2001 no solo mantuvo esta dualidad cautelar y sumaria sino que exacerbó algunas de sus incoherencias procesales e incluso introdujo otras nuevas. Si bien este proyecto comienza con una apuesta en favor de una concepción cautelar de la protección al afirmar que los procedimientos que allí se contemplan -tanto el de protección como el de habeas corpus - serán "públicos, breves, gratuitos e informales, teniendo la autoridad jurisdiccional competente la potestad para restablecer inmediatamente el imperio del derecho y los derechos afectados del justiciable" (art. 3 inciso 2) para lo cual se fijan algunas disposiciones como el impulso procesal de oficio (arts. 5 y 6), la prohibición de prorrogar los plazos (art. 7), el que estos sean continuos y una preferencia procesal en favor de la protección (art. 4) se trata de una aproximación cautelar que se diluye casi por completo cuando se expone la tramitación completa aplicable a la protección de derechos fundamentales. Esta tramitación corresponde básicamente a la de un juicio sumario con la "diferencia" de que se trata de un procedimiento inquisitivo ${ }^{120}$.

En cierto modo esta propuesta no es novedosa si se tiene en cuenta el rol que actualmente cumple el procedimiento sumario como juicio ordinario en la justicia civil chilena, es decir, como el procedimiento de aplicación común y supletoria en los casos en que la ley no ha regulado la tramitación o bien no lo ha hecho en forma completa (art. $3 \mathrm{CPC})^{121}$.

El problema aquí es otro y apunta a que esta tramitación sumaria se superpone a una estructura cautelar ordenada previamente por la Constitución de 1980 y con un fuerte arraigo en la jurisprudencia de la Corte Suprema.

Para dar cuenta de esta deficiencia basta con apreciar el modo en que el proyecto de 2001 reguló las fases de debate y decisión de la protección de derechos fundamentales. Junto con ello también es preciso hacer un breve comentario al modelo de procedimiento único que se sugirió varios años después durante la discusión parlamentaria de este mismo proyecto.

\section{a) DeBATE}

El proyecto de 2001 le dio competencia a la Corte de Apelaciones del domicilio del afectado (art. 32) en una regla novedosa para entonces pero que ha sido superada por la del Acta No 94 de 2015 cuyo derecho de opción para quien recurre ha mejorado sus estrategias de litigación.

118 Cazor y Rojas (2009) p. 182 (destacado en el original).

19 Gómez (2005) pp. 58, 81 y 234-236.

120 Carocca (2000) pp. 211-213.

121 Larroucau (2019b) pp. 1-41. 
El plazo para recurrir incluyó algunos matices que son útiles de considerar. Por un lado se amplió este plazo a sesenta días contados desde que cesan los efectos del acto y no desde que se toma conocimiento de su ocurrencia o del cese de tales efectos. De igual modo se contempló un plazo especial para la dimensión patrimonial de la privación, perturbación o amenaza del derecho afectado el cual es mayor que el plazo para la tutela de los derechos fundamentales: seis meses (art. 33). Este trato preferente con el aspecto patrimonial del caso se aleja por completo de la concepción cautelar del art. 20 de la Constitución de 1980 ya que es propia de un juicio declarativo civil ${ }^{122}$.

El proyecto también le reconoció legitimación activa a un organismo estatal para recurrir de protección: el Ministerio Público (art. 33, número repetido).

En cuanto a los criterios de inadmisibilidad de esta tutela judicial el proyecto consideró algunos que ya han sido reconocidos por la jurisprudencia: por ejemplo, que la amenaza no sea "real, realizable e inminente", que se recurra de sentencias de la Corte Suprema $^{123}$ o bien que se encuentre pendiente un fallo sobre los mismos hechos en un juicio entre las mismas partes (art. 35).

Este enfoque sumario de la protección se volvió ostensible cuando el proyecto dispuso que la Corte pueda ordenar a quien recurre que subsane los errores cometidos respecto de "requisitos en la interposición de la demanda" y que la rechace de plano en caso de no hacerlo (art. 34).

Por último, otras reglas que contribuyen a entender la protección como un juicio declarativo sumario son la que ordena evacuar los antecedentes solicitados por la Corte en el plazo de siete días (art. 44 inciso $1^{\circ}$ ) -un equivalente a la contestación de la demanda- y la que señala que la persona a quien afecte lo resuelto será considerada parte del juicio (art. 38).

\section{b) DeCISIÓN}

Las reglas del fallo de protección en el proyecto de 2001 también lo asemejaron a un juicio sumario ya que si la Corte no puede reestablecer el imperio del derecho -el objetivo original de la protección- debe imponer una indemnización de los daños sufridos en favor de quien recurrió (art. 52).

A pesar de esto la fisonomía cautelar subsistió en esta fase en cuanto se dispuso que el fallo favorable se cumpla dentro de las 48 horas desde que se encuentre firme (art. 54 inciso 2) y que se apele en el plazo de dos días (art. 56) en el solo efecto devolutivo (art. 9 inciso $1^{\circ}$ ).

\section{c) ¿UN PROCEDIMIENTO ÚNICO PARA TODAS LAS ACCIONES CONSTITUCIONALES?}

La discusión parlamentaria del proyecto de 2001 tuvo cambios importantes a través de dos indicaciones sustitutivas. La primera de ellas duplicó su extensión al incluir otras acciones contempladas por la Constitución de 1980 como la indemnización por error judicial

\footnotetext{
122 Palomo (2009) p. 346.

123 Ried (2015) pp. 271-320.
} 
y el reclamo de nacionalidad, así como algunas acciones reconocidas en leyes especiales con la intención de elaborar un "código de acciones protectoras de derechos fundamentales"124.

En lo que respecta a la protección de derechos fundamentales esta primera modificación solo introdujo algunas modificaciones como el plazo para recurrir -que volvió a ser de treinta días (art. 53 inciso $1^{\circ}$ ) - y la eliminación de los privilegios procesales si la recurrida es una autoridad pública (art. 58).

En junio del año 2007 la Corte Suprema evacuó un informe desfavorable a esta indicación sustitutiva (Oficio No 177). El motivo es que advirtió un déficit de garantías del debido proceso especialmente con respecto a la contradicción de partes ("el actor lleva ventaja, porque puede preparar con tiempo su presentación, hasta con la ayuda del juez") y la imparcialidad judicial ("se les impone [a los jueces] dictar sentencias en plazos absurdamente breves, tanto en primera como en segunda instancia, exigiéndose fallos detallados"). La Corte Suprema también acusó que esta tramitación haría de esta vía "el camino más fácil que los abogados tendrán para plantear cualquier conflicto, que puede ser fácilmente acomodado como violación a derechos fundamentales, con efectos que llevarán a imponer prestaciones directas y a indemnizaciones de perjuicios" ${ }^{125}$.

Los reparos de la Corte Suprema -tanto al proyecto original como a esta primera indicación sustitutiva - denotan una crítica a la fisonomía sumaria propuesta para la protección de derechos fundamentales, una forma de tramitación a la que ella misma ha propendido en sus autos acordados.

El debate legislativo de este proyecto se detuvo en noviembre del año 2008 cuando fue devuelto por la Cámara de Diputados a las Comisiones de Derechos Humanos, Nacionalidad y Ciudadanía y a la de Constitución, Legislación y Justicia para que se hiciesen cargo de los aspectos cuestionados. Este envío dio curso a una pausa que se extendió por una década ${ }^{126}$.

124 Cámara de Diputados, Legislatura 356a, Sesión 103a (18 de noviembre de 2008) p. 27.

125 En diciembre del año 2001 la Corte Suprema también había informado desfavorablemente el proyecto original al notar "serios inconvenientes tanto de forma como de fondo, al presentar vacíos y omisiones trascendentes y fundamentales para un texto que busca reglamentar instituciones constitucionales, a través de procedimientos judiciales [estimando que el proyecto] contiene disposiciones que se oponen entre sí, de modo tal que la contradicción de los preceptos no permite discernir la real voluntad del legislador sobre esos puntos [y que] existe confusión respecto de expresiones, conceptos jurídicos y sobre el rol jurisdiccional que cabe a los Tribunales de Justicia, en varios de sus artículos" (Oficio No 3.057). La Corte Suprema le sugirió al Congreso tomar en cuenta su auto acordado de 1998 porque a su juicio allí "se aplica satisfactoriamente y perfila a esta acción en su recta naturaleza”.

126 En el año 2017 se presentó un nuevo proyecto de ley que decía relación con la forma de tramitar la protección de derechos fundamentales (Boletín No 11.495-07). Este proyecto -de la senadora Carolina Goic- propuso cambiar la regulación del amparo económico (Ley No 18.971 de 1990) al entender que se trata de un privilegio injustificado que debería subsumirse como un caso más de protección del art. 20 de la Constitución de 1980. Al igual que en los intentos anteriores este proyecto de ley desplazó el carácter cautelar de la protección por una tramitación sumaria al proponer, por ejemplo, que se amplíe la legitimación activa a los intereses colectivos, que se aumenten los requisitos del escrito de protección, que se le reconozca al fallo de la Corte el carácter de sentencia definitiva y que dicha decisión judicial produzca el efecto de cosa juzgada formal. La Corte Suprema informó de un modo muy crítico este proyecto (Oficio No 26-2018) al cuestionar diversos aspectos del mismo, sobre todo los requisitos adicionales del escrito de protección los cuales "no tienen ninguna relación con el examen de admisibilidad [por lo que] parecieran constituir meras recomendaciones para el recurrente 
En el año 2019 el proyecto recibió una segunda indicación sustitutiva en base a un trabajo en que participó Raúl Tavolari. Esta indicación fue nuevamente informada de manera negativa por la Corte Suprema por su propuesta de crear "un procedimiento único de tramitación" para todas las acciones constitucionales: habeas corpus, protección, reclamo de nacionalidad, error judicial y extranjería (considerando 33, IX, No 1, Oficio No 119-2019).

Este "procedimiento único" se estructuraría en base a "etapas concentradas" en el siguiente orden: interposición, informe, recopilación de antecedentes, cuenta o vista de la causa, sentencia, recurso y procedimiento especial de cumplimiento. Como si fuese una acuarela de J. M. W. Turner esta segunda indicación sustitutiva difuminó con sus "etapas concentradas" las diferencias de tramitación entre la técnica cautelar y el procedimiento sumario con un problema adicional: las incongruencias procesales que hoy afectan a la protección del art. 20 de la Constitución de 1980 se contagiarán a las demás acciones constitucionales.

\section{CONCLUSIONES}

Este artículo analiza en forma crítica la dualidad cautelar y sumaria de la protección de derechos fundamentales en la litigación chilena. Las principales fuentes normativas de esta tensión son el art. 20 del texto constitucional de 1980 (cautelar) y la regulación mediante autos acordados de la Corte Suprema (sumaria). Las consecuencias procesales que se siguen de esta pugna atraviesan desde la formación del debate hasta el cumplimiento de lo resuelto.

Bajo un enfoque cautelar la protección es una vía judicial informal, unilateral, inquisitiva y concentrada que simplifica en extremo las formas de participación en tribunales y cuyo resultado provisorio excluye la idea de cosa juzgada en cualquiera de sus variantes. El principal soporte de esta concepción lo entrega el propio texto constitucional de 1980, el auto acordado de 1977 y una parte considerable de la jurisprudencia de la Corte Suprema que se refiere a esta vía como una tutela de urgencia.

Esta concepción cautelar se contradice con los importantes cambios introducidos en la tramitación de esta tutela judicial a lo largo de cuatro décadas y que le dan la fisonomía de un procedimiento contencioso sumario. Este enfoque sumario crea una serie de efectos procesales tanto en la fase de debate (tribunal competente, plazo para recurrir, legitimación activa, participación de terceros y orden de no innovar), prueba (las evidencias admisibles y su valoración) y decisión (cosa juzgada y sanciones) que modifican en la práctica su diseño original.

El referente normativo más claro de esta aproximación sumaria es el Acta No 94 del año 2015 y el proyecto de ley presentado en el Congreso el año 2001, incluidas sus dos indicaciones sustitutivas en los años 2007 y 2019.

La única forma de poner fin a la metamorfosis procesal de la protección de derechos fundamentales es a través de una ley que regule su procedimiento por lo que debe ser el Congreso quien aborde la difícil tarea de equilibrar el acceso a la justicia de quien pide una tutela inmediata y el derecho a un debido proceso de aquel en contra de quien se recurre.

[aunque] llama la atención la gran cantidad de menciones que deben hacerse, exigencias que parecen incompatibles con la posibilidad de accionar sin el patrocinio de un abogado" $\left(18^{\circ}\right)$. 
En cualquier caso, el camino escogido debe reflejarse en un diseño procesal coherente que honre el compromiso internacional que tiene el sistema jurídico chileno con la protección judicial de los derechos fundamentales.

\section{BIBLIOGRAFÍA CITADA}

Aldunate, Eduardo (1999): "La protección al acecho: Las consecuencias del abandono de las reglas de interpretación constitucional en el ámbito del recurso de protección”, Revista de Derecho de la Pontificia Universidad Católica de Valparaíso, vol. 20: pp. 225-242.

ANDRADES, Eduardo (1998): "Algunos comentarios al nuevo auto acordado sobre tramitación del recurso de protección", Revista Chilena de Derecho, No especial: pp. 121-125.

Bordalí, Andrés (2019): Litigación ambiental (Santiago de Chile, Thomson Reuters).

Bordalí, Andrés (2014): "El recurso de protección: todavía un fantasma jurídico (Tribunal Constitucional)", Revista de Derecho de la Universidad Austral, vol. 27, No 2: pp. 277-283.

Bordalí, Andrés (2007): "La tutela de los derechos fundamentales bajo un sistema dual de justicia constitucional”, en BORDAlí, Andrés (coord.), Justicia constitucional y derechos fundamentales (Santiago de Chile, LexisNexis) pp. 33-65.

Bordalí, Andrés (2004): "El recurso de protección como proceso de urgencia", Revista Chilena de Derecho, vol. 31, No 2: pp. 269-288.

Bordalí, Andrés (2003): "El debido proceso civil”, en Ferrada, Juan Carlos (coord.), La constitucionalización del derecho chileno (Santiago, Editorial Jurídica de Chile) pp. 251 295.

Bordalí, Andrés (2001): "Diversos significados de la tutela cautelar en el proceso civil", Revista de Derecho de la Universidad Austral, vol. 12: pp. 51-66.

Bordalí, Andrés (1999): "El proceso de protección", Revista de Derecho de la Universidad Austral, vol. 10, No 1: pp. 43-58.

Bustos, Rodrigo (2009): "Derechos sociales y recurso de protección: ¿Una relación difícil"?, Derecho y Humanidades (Universidad de Chile), No 15: pp. 231-247.

Carocca, Alex (2000): "Bases para fijar nuevos procedimientos para tramitar las acciones constitucionales protectoras de derechos fundamentales", en Nogueira, Humberto (coord.), Acciones constitucionales de amparo y protección: Realidad y prospectiva en Chile y América Latina (Talca, Editorial Universidad de Talca) pp. 201-213.

Cazor, Kamel y Rojas, Christian (2009): "Las deficiencias estructurales y prácticas de la acción de protección”, Revista de Derecho de la Universidad Católica del Norte, vol. 16, No 1: pp. 169-192.

Cerda, Victoriano (2001): "La muerte del recurso de protección”, Revista de Derecho Público (Universidad de Chile), No 63: pp. 380-401.

Cortez, Gonzalo (2017): La tutela cautelar en el proceso civil (Santiago de Chile, Thomson Reuters).

Díaz, Carlos y FaCuSE, Nicolás (2014): "El desarrollo jurisprudencial del concepto de amenaza como presupuesto procesal para la procedencia de la acción de protección", Revista de Derecho Público (Universidad de Chile), No 81: pp. 55-76. 
DomíngueZ, Ramón (1992): "Comentarios de jurisprudencia. Recurso de protección. Derecho adquirido del administrado. Ilegalidad de acto revocatorio de permiso ya concedido. Doctrina del acto propio", Revista de Derecho de la Universidad de Concepción, No 191: pp. 176-179.

Dougnac, Fernando (2001): "Reflexiones sobre la acción de protección y su sentencia", Revista Chilena de Derecho, vol. 28, No 3: pp. 615-630.

ERrÁzuriz, Juan Manuel y Otero, Jorge (1989): Aspectos procesales del recurso de protección (Santiago, Editorial Jurídica de Chile).

Gómez, Gastón (2005): Derechos fundamentales y recurso de protección (Santiago, Ediciones Universidad Diego Portales).

Henríquez, Miriam (2018): Acción de protección (Santiago de Chile, Cuadernos Jurídicos de la Academia Judicial).

Jana, Andrés y Marín, Juan Carlos (1996): El recurso de protección y contratos (Santiago, Editorial Jurídica de Chile).

LARROUCAU, Jorge (2020): "Los límites procesales de la protección de derechos fundamentales y el filtro de admisibilidad en la Corte de Apelaciones", Revista de Derecho de la Universidad Católica del Norte, vol. 27, No 1: pp. 1-41.

LARroucau, Jorge (2019a): "La expansión procesal de la protección de derechos fundamentales en Chile", Revista de Derecho Privado (Universidad de Externado de Colombia), No 37: pp. 249-282.

LARROUCAU, Jorge (2019b): "El juicio sumario como procedimiento ordinario en la justicia civil chilena", Revista de la Facultad de Derecho (Universidad de la República, Uruguay), No 46: pp. 1-41.

LARrouCAU, Jorge (2017): "Adiós a las fojas. Reglas procesales, autos acordados y tramitación electrónica en Chile", Revista de Derecho Privado (Universidad de Externado, Colombia), No 33: pp. 195-234.

LEWIS, Sebastián (2013): "Sobre la legitimación de los órganos del Estado para interponer un recurso de protección y alzarse judicialmente en contra del órgano contralor", Revista de Derecho Administrativo, No 8: pp. 129-152.

Machado, Priscila (2019): "La cosa juzgada material secundum eventum probationis en la acción constitucional de protección”, Revista Chilena de Derecho, vol. 46, No 3 : pp. 741-764.

Marín, Juan Carlos (2016): Tratado de las medidas cautelares. Doctrina, jurisprudencia, antecedentes históricos y Derecho comparado (Santiago, Editorial Jurídica de Chile, 2a Ed.).

Nogueira, Humberto (2007): "El recurso de protección en el contexto del amparo de los derechos fundamentales Latinoamericano e interamericano", Ius et Praxis, vol. 13, No 1: pp. 75-134.

OBERG, Héctor (1987): "La orden de no innovar", Revista de Derecho de la Universidad de Concepción, No 181: pp. 57-62.

PAillás, Enrique (2002): El recurso de protección ante el derecho comparado. Una acción en busca de una justicia rápida y eficaz (Santiago, Editorial Jurídica de Chile, $3^{\text {a }}$ Ed. actualizada).

Palomo, Diego (2009): "Recurso de protección en Chile: luces, sombras y aspectos que requieren cambios", en Nogueira, Humberto y Bordalí, Andrés (coords.), La ciencia 
del derecho procesal constitucional. Estudios en homenaje a Héctor Fix-Zamudio en sus cincuenta años como investigador del derecho (Santiago de Chile, CECOCH, Librotecnia) pp. 335-396.

Paredes, Felipe (2014): La garantía jurisdiccional de los derechos fundamentales (Santiago de Chile, Thomson Reuters).

Parodi, Alejandro (2014): “Tribunal Constitucional: ¿Facultades legislativas de la Corte Suprema?”, en LyD (edit.), Sentencias destacadas 2013 (Santiago de Chile, Libertad y Desarrollo) pp. 279-298.

Pereira, Hugo (1997): La cosa juzgada en el proceso civil (Santiago de Chile, Editorial Jurídica ConoSur, 2a Ed.).

Pérez, Álvaro (2017): “Tutela sumaria de derechos en el proceso civil: Misión y visión en Latinoamérica”, Revista Chilena de Derecho Privado, No 28: pp. 137-182.

PINOChet, Francisco (2016): El recurso de protección. Estudio profundizado y actualización sobre sus origenes, evolución, doctrina, jurisprudencia y derecho comparado (Santiago de Chile, Editorial El Jurista).

PRECHT, Jorge (1992): "La supremacía constitucional y los autos-acordados", Revista de Derecho de la Universidad Austral, vol. 3, No 1-2: pp. 53-64.

Ried, Ignacio (2015): "El recurso de protección como control de constitucionalidad de las resoluciones y sentencias civiles, en respuesta a la ineficacia de la acción de inaplicabilidad por inconstitucionalidad", Estudios Constitucionales, vol. 13, No 1: pp. 271-320.

Ríos, Lautaro (1994): "El recurso de protección y sus innovaciones procesales", Revista de Derecho y Jurisprudencia, tomo 91, No 1: pp. 43-58.

Rivero, Renée (2019): "La tutela meramente declarativa o de mera certeza y su reconocimiento en el sistema procesal civil chileno", Ius et Praxis, vol. 25, No 1: pp. 89-130.

Romero, Alejandro (2014): Curso de derecho procesal civil. La acción y la protección de los derechos (Santiago de Chile, Thomson Reuters, 2a Ed.).

Romero, Alejandro (2002): La cosa juzgada en el proceso civil chileno. Doctrina y jurisprudencia (Santiago, Editorial Jurídica de Chile).

Romero, Alejandro (1999): "Notas sobre la cosa juzgada en el recurso de protección", Revista Chilena de Derecho, vol. 26, No 2: pp. 503-515.

SAlas, Carolina (2011): "Sobre la (in)constitucionalidad del Auto Acordado que regula la tramitación y fallo del recurso de protección. Un comentario a la sentencia rol 1557 del Tribunal Constitucional", Revista de Derecho de la Universidad Católica del Norte, vol. 18, No 2: pp. 417-427.

SCHIESSLER, Guillermo (1982): "Algunas cuestiones relativas al recurso de protección”, Revista de Derecho de la Pontificia Universidad Católica de Valparaiso, vol. 6: pp. 353-368.

Soto, Eduardo (1985): "Recurso de protección y tribunal competente. ¿Cuál es la Corte de Apelaciones respectiva?", Revista de Derecho Público (Universidad de Chile), No 37 y 38 : pp. 187-200.

Soto, Eduardo (1984): “Cosa juzgada y recurso de protección”, Gaceta Jurídica No 50: pp. 3-14.

Soто, Eduardo (1982): El recurso de protección. Orígenes, doctrina y jurisprudencia (Santiago, Editorial Jurídica de Chile). 
TAVOlari, Raúl (2000): “Tramitación de la acción constitucional chilena de protección”, en Raúl Tavolari: El proceso en acción (Santiago de Chile, Editorial Libromar), pp. 459-530. TAVOLARI, Raúl (1994): "Protección constitucional y cautela judicial. ¿Orden de no innovar en el recurso de protección?”, en TAVOLARI, Raúl (edit.), Tribunales, jurisdicción y proceso (Santiago, Editorial Jurídica de Chile) pp. 137-168.

Vergara, Alejandro (1991): "La propietarización de los derechos", Revista de Derecho de la Pontificia Universidad Católica de Valparaíso, vol. 14: pp. 281-291.

ZúNIGA, Francisco (2011): "Control de constitucionalidad de autos acordados", Estudios Constitucionales, vol. 9, No 1: pp. 389-418.

ZúNiga, Francisco (1997): "Recurso de protección y contencioso administrativo", Revista de Derecho de la Universidad de Concepción, No 202: pp. 105-119.

ZúNIGA, Francisco (1996): "Recurso de protección: Algunas notas sobre sus antecedentes históricos en el siglo XIX", Gaceta Jurídica, No 18: pp. 7-14.

\section{JURISPRUDENCIA CITADA}

Luksic con Martorell y Editorial Planeta (1993): Corte de Apelaciones de Santiago, 31 de mayo de 1993 (protección), Rol No 21.053.

Lebanon Investment Corporation Chile con Sauna Hermanos Ltda. (1997): Corte de Apelaciones de Santiago, 22 de julio de 1997 (protección), Revista de Derecho y Jurisprudencia, tomo 84, sección 2a, No 2, pp. 84-85.

Philippi y otros con Laboratorio Chile S.A. (2001): Corte Suprema, 30 de agosto de 2001 (protección), Rol No 2186-01.

REQUERIMIENTO POR INCONSTITUCIONALIDAD DE ISAPRE CRUZ BLANCA S.A. RESPECTO DEL APARTADO $11^{\circ}$ DEL AUTO ACORDADO SOBRE TRAMITACIÓN Y FALLO DEL RECURSO DE PROTECCIÓN, DE las Garantías Constitucionales dictado por la Corte Suprema, en RELACIÓN al ROL DE INGRESO No 765 - 2009 PENDIENTE EN LA CORTE DE APELACIONES DE SANTIAGO (2011): Tribunal Constitucional, 14 de abril de 2011 (inconstitucionalidad), Rol No 1557-2011.

Tobar con IsApre CRUZ Blanca S. A. (2011): Tribunal Constitucional, 18 de agosto de 2011 (inaplicabilidad), Rol No 1812.

Municipalidades de Santiago y otras con Contraloría General de la República (2012): Corte Suprema, 6 de noviembre de 2012 (protección), Rol No 5984-2012 (redacción del ministro Juan Escobar; voto en contra de la ministra Rosa Egnem y del abogado integrante Jorge Baraona).

REQUERIMIENTO DE INCONSTITUCIONALIDAD PRESENTADO POR EDUARDO IGNACIO MARTÍNEZ MAchuca, Alcalde de la I. Municipalidad de La Calera, Respecto del artículo 15 del Auto Acordado sobre Tramitación y Fallo del Recurso de Protección de las Garantías Constitucionales de la Corte Suprema, en los autos sobre reCURSo de protecCión, CARATUlados "Corporación UNIVERSIDAD DE ACONCAGUA CONTRA ILUSTRE MUNiCIPALIDAD de La Calera”, Rol No 121-2011, de la Corte de Apelaciones de Valparaíso, en aCtUal APELACIÓN ANTE CoRTE SUPREMA, BAJO EL ROL No 3866-2012 (2013): Tribunal Constitucional, 3 de septiembre de 2013 (inconstitucionalidad), Rol No 2243-2013. 
REQUERIMIENTO DE INAPLICABILIDAD PRESENTADO POR CRISTIAN HERRERA Y RAÚl SCHIFFERLI RESPECTO DE LA LETRA B) DEL INCISO $2^{\circ}$ DEL ARTÍCULO 75 DE LA LEY No 18.695 (2014): Tribunal Constitucional, 9 de septiembre de 2014 (inaplicabilidad), Rol No 2538-2013.

Vergara y Morales con Superintendencia de Medio Ambiente V Región (2015): Corte de Apelaciones de Valparaíso, 30 de octubre de 2015 (protección), Rol No 3.137-2015.

Consejo de Autoridades Ancestrales del Pueblo Nación Mapuche "Nisol Gnulam" con Dirección General de Territorio Marítimo y Marina Mercante de la Armada de Chi$L E$ (2016): Corte de Apelaciones de Valparaíso, 20 de abril de 2016 (protección), Rol No $1.257-2016$.

VÁsquez con Universidad Academia Humanismo CRIStiano (2016): Corte de Apelaciones de Talca, 14 de abril de 2016 (protección), Rol No 489-2016 (Primera Sala: redacción del abogado integrante Iván Obando; voto en contra del ministro Carlos Carrillo).

Conejera con Hospital Clínico de la Universidad de Chile (2017): Corte Suprema, 20 de diciembre de 2017 (protección), Rol No 37.809-2017.

Gonzalez y otros con ILUstre Municipalidad de LAs Condes (2017): Corte de Apelaciones de Santiago, 21 de agosto de 2017 (protección), Rol No 34.360-2017 (redacción de la ministra Mireya López).

Gonzalez y otros con Ilustre Municipalidad de LAS Condes (2017): Corte Suprema, 11 de diciembre de 2017 (protección), Rol No 38.527-2017.

Jerez CON Asociación Chilena de SeGURIDAd (2017): Corte de Apelaciones de Santiago, 8 de agosto de 2017 (protección), Rol No 47.987-2017.

Korol con Bío-Bío Comunicaciones S.A. y otros (2017): Corte de Apelaciones de Santiago, 15 de marzo de 2017 (protección), Rol No 3.991-2017.

Korol Con BÍ-BÍo ComunicaCiones S.A. y otros (2017): Corte Suprema, 30 de octubre de 2017 (protección), Rol No 11.745-2017.

Martínez con Condominio Parque Bulnes (2017): Corte de Apelaciones de Santiago, 13 de noviembre de 2017 (protección), Rol No 75.274-2017 (Primer Sala).

Martínez con Condominio Parque Bulnes (2017): Corte Suprema, 6 de diciembre de 2017 (protección), Rol No 43.374-2017 (Tercera Sala).

Maza con Promotora CMR Falabella S.A. (2017): Corte de Apelaciones de Santiago, 23 de noviembre de 2017 (protección), Rol No 42.653-2017 (Novena Sala: redacción de la abogada integrante Claudia Chaimovich).

Valdivia con Corporación de Asistencia Judicial de la Región Metropolitana (2017): Corte de Apelaciones de Talca, 29 de septiembre de 2017 (protección), Rol No 2562017, (Primera Sala).

BARRAZA CON AFP CUPRUM S.A. (2019): Corte de Apelaciones de Iquique, 24 de julio de 2019 (protección), Rol No 314-2019. 
